\title{
Assessment of a rolling isolation system using reduced order structural models
}

\author{
P. Scott Harvey Jr., ${ }^{\mathrm{a}, *}$, Henri P. Gavin ${ }^{\mathrm{b}}$ \\ ${ }^{a}$ School of Civil Engineering and Environmental Science, University of Oklahoma, Norman, Oklahoma 73019, USA \\ ${ }^{b}$ Department of Civil and Environmental Engineering, Duke University, Durham, North Carolina 27708, USA
}

\begin{abstract}
This paper examines the performances of lightly- and heavily-damped rolling isolation systems (RISs) located within earthquake-excited structures. Six steel structures of varying height and stiffness are selected so as to represent a range of potential RIS installations. Computation models of representative frames from each of the six structures are reduced through dynamic condensation and assembled with models for biaxial isotropic hysteretic behavior within each floor. A novel reduced order modeling approach is presented in this paper. The method combines a dynamic condensation of a linear-elastic frame with the inelastic-push over curve for a detailed elastic-plastic frame model and a novel bi-axial hysteretic model for the net inter-story inelastic behavior. The reduced inelastic model combines stiffness and mass matrices from the reduced linear model with the bi-axial inelastic floor model, and is subsequently fit to push-over curves from the detailed hysteretic model. The resulting reduced order model has three coordinates per floor and provides a much simpler means for simulating the floor responses of inelastic structures. The resulting inelastic structural models are isotropic in plan and uniform along the height. Suites of recorded ground motions representative of near-fault and far-field hazards are scaled and inputted into these hysteretic reduced models. The bidirectional floor responses at varying heights are then applied to experimentally-validated models of lightly- and heavily-damped RISs. Empirical cumulative distribution functions of peak isolator responses (relative displacement and total acceleration) for the two systems are compared, from which installation guidelines are presented.
\end{abstract}

Keywords: equipment isolation, seismic hazard, rolling isolation system, model reduction, hysteresis, nonstructural component

\section{Introduction}

Performance-based aseismic design of new buildings aims to ensure structural integrity, immediate occupancy, and operational performance levels following an earthquake. Critical facilities, such as emergency response centers and hospitals [1], must remain functional during and after major earthquakes for the public welfare and safety. However, the functionality of these critical facilities is not solely dictated by the structure's integrity, but instead must also

\footnotetext{
${ }^{*}$ Corresponding author. Address: University of Oklahoma, School of Civil Engineering and Environmental Science, 202 W Boyd St, Room 334, Norman, OK 73019, USA. Tel.: +1 4053253836

Email addresses: harvey@ou.edu (P. Scott Harvey Jr.), hpgavin@duke .edu (Henri P. Gavin)
} 
consider damages to the building contents - which typically occur at lower levels of shaking intensity than structural damage. Even in the absence of damage to structural components, the services these buildings provide should also remain uninterrupted. Disruption of services in data centers, telecommunication networks, industrial facilities, or technology centers may result in major direct and indirect economic losses [2, 3].

The societal and economic impacts of damage to valuable or mission-critical building contents - such as medical equipment, computer servers, or priceless artifacts — can far outweigh the cost of the building itself [4]. For the protection of such vibration-sensitive components, seismic isolation has steadily gained interest in the engineering community [5]. Seismic isolation reduces the seismic demand on structures and their contents by decoupling the motion of the structure (equipment) from the harsh base (floor) motion [6]. Seismic isolation has been successfully implemented at various scales - from the entire structure [7-12], to floors within the structure [13-16], and down to the component level [17, 18].

This work focuses on assessing the performance of rolling isolation systems (RISs) used to protect individual pieces of equipment. Previous studies have been carried out to assess the in-building performance of isolated objects, but were limited to planar structural responses and unidirectional excitations [13-18]. RISs are known to exhibit strong coupling between transverse (and rotational) responses [19]. Furthermore, ground motions, structural responses, and equipment responses are inherently multidirectional. This paper addresses the bidirectional (horizontal $x$ and y) response of RISs in situ, subjected to simulated floor responses of a variety of building heights, stiffnesses, and ductility excited by recorded ground motions. An extensive parameter study, involving time history analyses (as opposed to floor response spectra [11]), is facilitated by a new hysteretic model reduction technique, alleviating the computation demands of dynamic finite element simulations of the building response.

Previous methods of model reduction for hysteretic structures have either (a) been limited to reducing only the linear aspects of the system (retaining all the nonlinear elements present in the system at some computational expense) $[20,21]$ or (b) approximated the nonlinear system using modal superposition with time-varying modes [22, 23]. In the reduced-order modeling method presented here, the elastic restoring forces of a condensed linear model are simply replaced by hysteretic forces. The reduced linear model is computed via dynamic condensation [24]. The coordinates of the condensed model correspond to selected coordinates of the full model, and the condensed model matches the full model at any selected frequency. The hysteretic forces are evolutionary $[25,26]$ and are calibrated to match the push-over behavior of the detailed inelastic frame model. Note that the number of hysteretic variables need not be larger than the number of condensed coordinates and time-varying (or 'nonlinear') modes are not involved.

This paper builds upon the comparison presented in Ref. [27] by examining the performances of a lightly-damped RIS and a heavily-damped RIS located within earthquake-excited structures (Figure 1). Six structures of varying height and stiffness [28] are chosen to represent a range of potential RIS installations, and finite element (FE) models of the six structures are first derived for representative planar frames (see Section 2). Then (Section 3) the proposed hysteretic model reduction method is described, which involves first reducing the full FE models via dynamic condensation, and then incorporating the three-dimensional (3D) models with hysteretic coupling in orthogonal directions. 


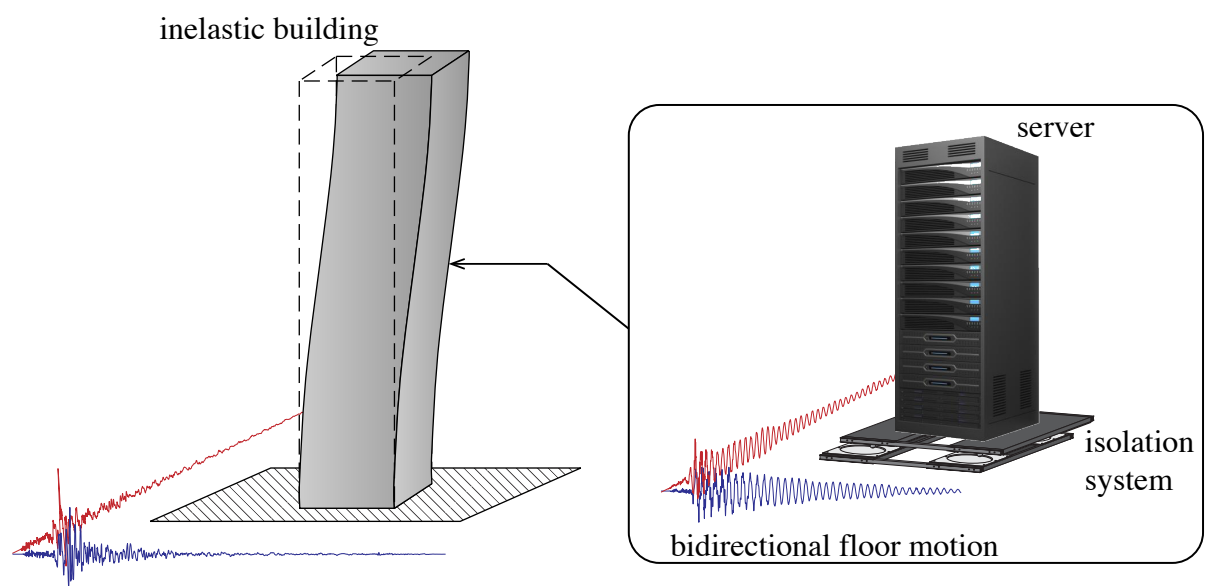

bidirectional ground motion

Figure 1: Model of an inelastic building, subjected to bidirectional ground motion, equipped with an isolation system.

Section 4 describes three suites of ground-motion records that are scaled and inputted into the reduced hysteretic models. Finally (Section 5) the performance of RISs, located at varying heights within the buildings, is assessed. The bidirectional floor responses of the seismically excited building are applied to the experimentally-validated models for lightly- and heavily-damped RISs [19, 27], and empirical cumulative distribution functions (CDFs) of peak equipment responses (accelerations and displacements) are compared and design guidelines are presented.

\section{Structural systems considered}

The buildings considered in this study are six steel moment-resisting frame building with 4, 8, and 12 stories designed and analyzed by Santa-Anna and Miranda [28]. As indicated in Fig. 2, these building have three bays at $7.32 \mathrm{~m}$ with uniform mass distribution over their height. For each of the aforementioned heights, two different buildings are considered: one is designed to be relatively flexible and the other to be relatively rigid. All are designed using the lateral load distribution specified in the 1994 Uniform Building Code for Zone IV. The rigidities of their beams and columns were tuned to obtain fundamental periods of vibration that are representative of existing steel buildings in California.

The complete models of the six buildings are briefly reviewed here. The $i^{\text {th }}$ node of a planar-frame model of a threebay, $n$-story buildings ( $n=4,8$, and 12 , see Fig. 2) possesses three degrees of freedom (DOF) - lateral displacement $x_{i}$, vertical displacement $z_{i}$, and rotation $\varphi_{i}$ - resulting in $3 \times 4 \times n$ DOF in total. The lateral displacements $x_{i}$ are measured relative to the ground. Let $\mathbf{d}=\left[x_{1}, z_{1}, \varphi_{1}, \ldots, x_{4 n}, z_{4 n}, \varphi_{4 n}\right]^{\top}$ be the $12 n$-dimensional vector of displacements and rotations, and $\mathbf{M} \in \mathbb{R}^{12 n \times 12 n}$ and $\mathbf{K} \in \mathbb{R}^{12 n \times 12 n}$ the corresponding mass and stiffness matrices. The differential equations governing the response of the building to horizontal ground motion $\ddot{u}_{\mathrm{g}}(t)$ are as follows:

$$
\mathbf{M d}+\mathbf{K d}=-\mathbf{M} u \ddot{u}_{\mathrm{g}}
$$



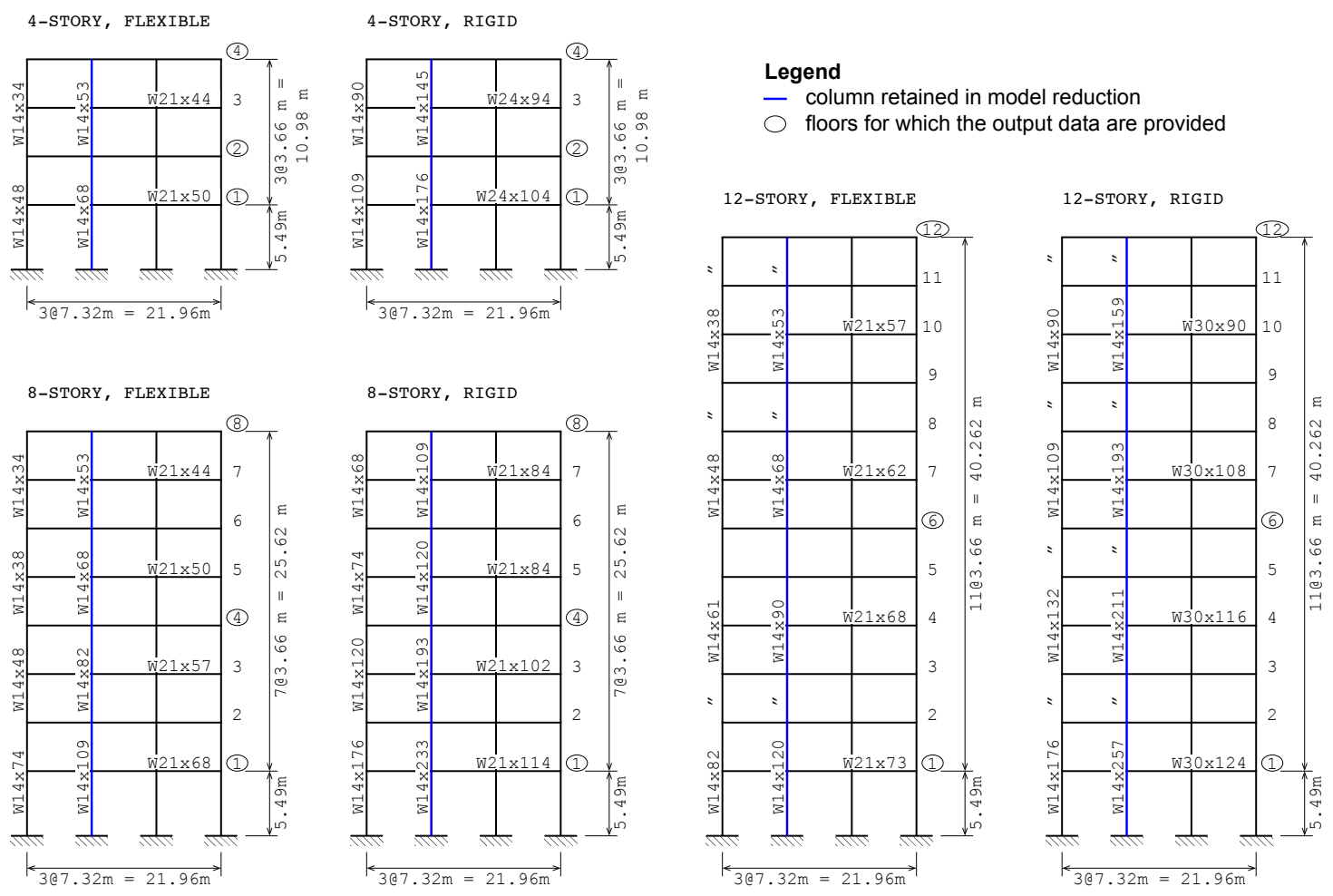

Figure 2: Planar frames used as representative designs [29] and levels for which floor acceleration data were recorded.

where the influence vector,

$$
\boldsymbol{\imath}=\left[\begin{array}{lll|lll|l|lll}
1 & 0 & 0 & 1 & 0 & 0 & \cdots & 1 & 0 & 0
\end{array}\right]^{\top} \in \mathbb{R}^{12 n},
$$

applies $\ddot{u}_{\mathrm{g}}$ to the lateral nodal displacement $x_{i}$.

The mass and stiffness matrices of the planar frames (Fig. 2) were generated using FrAmE3DD [30]. Additional mass was required in order for the natural periods to match those those reported by Santa-Anna and Miranda [29]. To wit, the necessary additional floor mass was determined by varying the added mass applied to the (horizontal) girder elements until the first natural period matched those of Ref. [29]. Table 1 gives the added mass and the first four natural frequencies of the frames considered.

The complete model (M, K) discussed here is for a planar frame. In order to evaluate the equipment isolation performance for bidirectional motion, a coupled model of the building's $x$ - and $y$-responses will be developed (Section 3.3). Coupling the orthogonal frame models doubles the model size, which may be computationally expensive to simulate, especially because the planar frame models are themselves large $(12 \times$ the number of stories). Because timehistory analyses of the buildings' responses will be used to carry out the detailed evaluation of the equipment isolation performance, model reduction is desired, if not required. The next section describes a model reduction technique that incorporates bidirectional responses through a biaxial hysteresis model. 


\section{Model reduction for hysteretic systems}

In this section, a novel model reduction technique for hysteretic systems is presented. The technique involves: (i) reducing the complete model through dynamic condensation, (ii) incorporating modal damping into the reduced model, and (iii) coupling the bidirectional response via a biaxial hysteresis model. The hysteretic reduced threedimensional model is verified via pushover analysis.

\subsection{Dynamic Guyan condensation}

First, the complete model (M, K) is reduced through dynamic Guyan condensation [31], whereby dynamics at a selected frequency $(\omega)$ are matched exactly. Let $\mathbf{d}_{\mathrm{p}}$ be the primary coordinates that are to be retained, and $\mathbf{d}_{\mathrm{s}}$ the secondary coordinates that are eliminated. In this case, we take $\mathbf{d}_{\mathrm{p}}$ to be the $n$-dimensional vector of the lateral nodal displacements of the column second from the left (indicated in Fig. 2) and $\mathbf{d}_{\mathrm{s}}$ the remaining $11 n$ DOFs. The equations (1) of motion can be transformed and partitioned as follows:

$$
\left[\begin{array}{cc}
\mathbf{M}_{\mathrm{pp}} & \mathbf{M}_{\mathrm{ps}} \\
\mathbf{M}_{\mathrm{sp}} & \mathbf{M}_{\mathrm{ss}}
\end{array}\right]\left\{\begin{array}{l}
\ddot{\mathbf{d}}_{\mathrm{p}} \\
\ddot{\mathbf{d}}_{\mathrm{s}}
\end{array}\right\}+\left[\begin{array}{ll}
\mathbf{K}_{\mathrm{pp}} & \mathbf{K}_{\mathrm{ps}} \\
\mathbf{K}_{\mathrm{sp}} & \mathbf{K}_{\mathrm{ss}}
\end{array}\right]\left\{\begin{array}{l}
\mathbf{d}_{\mathrm{p}} \\
\mathbf{d}_{\mathrm{s}}
\end{array}\right\}=-\left[\begin{array}{cc}
\mathbf{M}_{\mathrm{pp}} & \mathbf{M}_{\mathrm{ps}} \\
\mathbf{M}_{\mathrm{sp}} & \mathbf{M}_{\mathrm{ss}}
\end{array}\right]\left\{\begin{array}{l}
\boldsymbol{t}_{\mathrm{p}} \\
\boldsymbol{t}_{\mathrm{s}}
\end{array}\right\} \ddot{u}_{\mathrm{g}}
$$

Assuming free-response solutions $\mathbf{d}_{\mathrm{p}}(t)=\overline{\mathbf{d}}_{\mathrm{p}} \sin \omega t$ and $\mathbf{d}_{\mathrm{s}}(t)=\overline{\mathbf{d}}_{\mathrm{s}} \sin \omega t$, the partitioned eigenvalue problem is

$$
\left[\begin{array}{ll}
\mathbf{K}_{\mathrm{pp}}-\omega^{2} \mathbf{M}_{\mathrm{pp}} & \mathbf{K}_{\mathrm{ps}}-\omega^{2} \mathbf{M}_{\mathrm{ps}} \\
\mathbf{K}_{\mathrm{sp}}-\omega^{2} \mathbf{M}_{\mathrm{sp}} & \mathbf{K}_{\mathrm{ss}}-\omega^{2} \mathbf{M}_{\mathrm{ss}}
\end{array}\right]\left\{\begin{array}{l}
\overline{\mathbf{d}}_{\mathrm{p}} \\
\overline{\mathbf{d}}_{\mathrm{s}}
\end{array}\right\}=\left\{\begin{array}{l}
\mathbf{0} \\
\mathbf{0}
\end{array}\right\}
$$

The condensation transformation matrix is [31]

$$
\mathbf{T}=\left[\begin{array}{c}
\mathbf{I}_{n \times n} \\
-\left(\mathbf{K}_{\mathrm{ss}}-\omega^{2} \mathbf{M}_{\mathrm{ss}}\right)^{-1}\left(\mathbf{K}_{\mathrm{sp}}-\omega^{2} \mathbf{M}_{\mathrm{sp}}\right)
\end{array}\right]_{12 n \times n} \Rightarrow\left\{\begin{array}{l}
\mathbf{d}_{\mathrm{p}} \\
\mathbf{d}_{\mathrm{s}}
\end{array}\right\}=\mathbf{T} \mathbf{d}_{\mathrm{p}}
$$

\begin{tabular}{|c|c|c|c|c|c|c|c|c|c|c|}
\hline & & \multirow{2}{*}{$\begin{array}{l}\text { Added } \\
\text { mass } \\
{\left[10^{3} \mathrm{~kg}\right]}\end{array}$} & \multicolumn{4}{|c|}{$\begin{array}{l}\text { Full model }(\mathbf{M}, \mathbf{K}) \\
\text { natural frequencies }[\mathrm{Hz}]\end{array}$} & \multicolumn{4}{|c|}{$\begin{array}{l}\text { Reduced model }(\tilde{\mathbf{M}}, \tilde{\mathbf{K}}) \\
\text { natural frequencies }[\mathrm{Hz}]\end{array}$} \\
\hline & & & $f_{\mathrm{n} 1}$ & $f_{\mathrm{n} 2}$ & $f_{\mathrm{n} 3}$ & $f_{\mathrm{n} 4}$ & $\tilde{f}_{\mathrm{n} 1}$ & $\tilde{f}_{\mathrm{n} 2}$ & $\tilde{f}_{\mathrm{n} 3}$ & $\tilde{f}_{\mathrm{n} 4}$ \\
\hline \multirow{2}{*}{ 4-story } & flexible & 20.8 & 0.79 & 2.50 & 4.76 & 6.92 & 0.79 & 2.52 & 4.91 & 7.32 \\
\hline & rigid & 19.5 & 1.37 & 4.39 & 8.33 & 12.06 & 1.37 & 4.44 & 8.69 & 12.96 \\
\hline \multirow{2}{*}{8 -story } & flexible & 20.6 & 0.52 & 1.47 & 2.53 & 3.73 & 0.52 & 1.47 & 2.56 & 3.80 \\
\hline & rigid & 19.5 & 0.85 & 2.36 & 4.17 & 6.01 & 0.85 & 2.37 & 4.22 & 6.15 \\
\hline \multirow{2}{*}{12 -story } & flexible & 20.7 & 0.38 & 1.07 & 1.85 & 2.65 & 0.38 & 1.08 & 1.85 & 2.67 \\
\hline & rigid & 19.8 & 0.65 & 1.86 & 3.21 & 4.62 & 0.65 & 1.87 & 3.25 & 4.72 \\
\hline
\end{tabular}

Table 1: Natural frequencies for frames considered in both the full model and the reduced model. 
Applying the condensation matrix $\mathbf{T}$ to Equation (2), the reduced model is as follows:

$$
\tilde{\mathbf{M}} \ddot{\mathbf{d}}_{\mathrm{p}}+\tilde{\mathbf{K}} \mathbf{d}_{\mathrm{p}}=-\tilde{\mathbf{m}} \ddot{u}_{\mathrm{g}}
$$

where the reduced mass and stiffness matrices and mass allocation vector are

$$
\tilde{\mathbf{M}}=\mathbf{T}^{\boldsymbol{\top}}\left[\begin{array}{ll}
\mathbf{M}_{\mathrm{pp}} & \mathbf{M}_{\mathrm{ps}} \\
\mathbf{M}_{\mathrm{sp}} & \mathbf{M}_{\mathrm{ss}}
\end{array}\right] \mathbf{T}, \quad \tilde{\mathbf{K}}=\mathbf{T}^{\boldsymbol{\top}}\left[\begin{array}{cc}
\mathbf{K}_{\mathrm{pp}} & \mathbf{K}_{\mathrm{ps}} \\
\mathbf{K}_{\mathrm{sp}} & \mathbf{K}_{\mathrm{ss}}
\end{array}\right] \mathbf{T}, \quad \tilde{\mathbf{m}}=\mathbf{T}^{\boldsymbol{\top}}\left[\begin{array}{cc}
\mathbf{M}_{\mathrm{pp}} & \mathbf{M}_{\mathrm{ps}} \\
\mathbf{M}_{\mathrm{sp}} & \mathbf{M}_{\mathrm{ss}}
\end{array}\right]\left[\begin{array}{c}
\boldsymbol{\iota}_{\mathrm{p}} \\
\boldsymbol{l}_{\mathrm{s}}
\end{array}\right]
$$

The reduced model $(\tilde{\mathbf{M}}, \tilde{\mathbf{K}})$ exactly matches the modal dynamics at $\omega$, which can be any frequency. We select $\omega=\omega_{\mathrm{n} 1}$, the fundamental natural frequency of the full model $(\mathbf{M}, \mathbf{K})$. In so doing, the dimension of the model is reduced by a factor of 12 (complete: $12 n$ DOF; reduced: $n$ DOF). The first four natural frequencies of the reduced model are given in Table 1. A good match is found between the first few natural frequencies, with divergence in the higher modes. The reduced model can be thought of as a stick model with communication between all the stories, i.e. $\tilde{\mathbf{M}}$ and $\tilde{\mathbf{K}}$ are diagonally dominant and fully populated, in general.

\subsection{Extended Rayleigh damping}

Classical damping, in the form of extended Rayleigh damping [32], is incorporated into the reduced model (Equation (5)). A proportional damping matrix can be made up of a combination of the mass and stiffness matrices, as follows:

$$
\tilde{\mathbf{C}}=\sum_{p \in \mathcal{P}} c_{p} \tilde{\mathbf{M}}\left(\tilde{\mathbf{M}}^{-1} \tilde{\mathbf{K}}\right)^{p}
$$

in which the coefficients $c_{p}$ are arbitrary. The powers $p$ determine the bases, given by $\tilde{\mathbf{M}}\left(\tilde{\mathbf{M}}{ }^{-1} \tilde{\mathbf{K}}\right)^{p}$, over which $\tilde{\mathbf{C}}$ is expanded. Rayleigh damping is a limiting case of Equation (6) in which only the terms with $p=0$ and $p=1$ are retained in the series.

The generalized damping ratio associated with any mode $\omega_{m}$ is

$$
\zeta_{m}=\frac{1}{2 \omega_{m}} \sum_{p \in \mathcal{P}} c_{p} \omega_{m}^{2 p}
$$

By selecting the powers $p$, a set of $\omega_{m}$ (which need not be the natural frequencies), and the corresponding $\zeta_{m}$, the coefficients $c_{p}$ are evaluated for the simultaneous solution of Equation (7). The desired damping ratios $\zeta_{m}$ are obtained exactly at the specified frequencies $\omega_{m}$, and is approximated at intermediate frequencies.

The powers $\mathcal{P}=\{-1,0,+1,+2,+3\}$ were selected for all cases. Note that for the 4-story frames $(n=4)$ an additional frequency was needed to be able to uniquely solve for the coefficients; the five frequencies and damping ratios used are

$$
\begin{aligned}
& \omega=\left[\begin{array}{lllll}
\omega_{\mathrm{n} 1} & \left(\omega_{\mathrm{n} 1}+\omega_{\mathrm{n} 2}\right) / 2 & \omega_{\mathrm{n} 2} & \omega_{\mathrm{n} 3} & \omega_{\mathrm{n} 4}
\end{array}\right] \\
& \zeta=\left[\begin{array}{lllll}
0.01 & 0.01 & 0.01 & 0.012 & 0.05
\end{array}\right]
\end{aligned}
$$




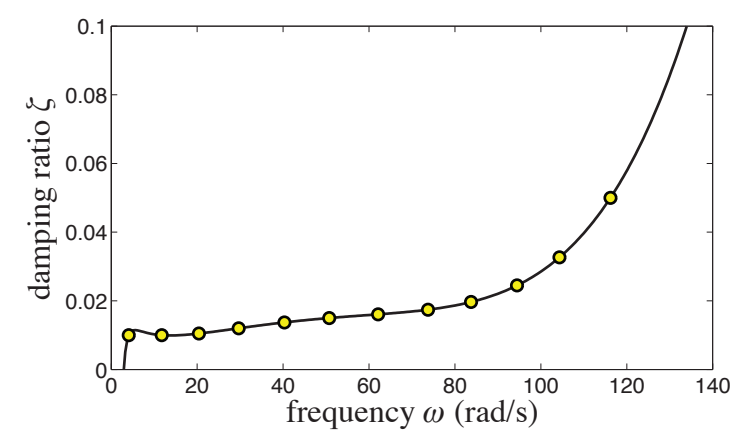

Figure 3: Extended Rayleigh damping (damping ratio versus frequency) for the 12-story, rigid frame: (一) polynomial fit, (०) natural frequencies $\omega_{\mathrm{n} i}$.

where $\omega_{\mathrm{n} i}$ is the $i$ th natural frequency of the system in Equation (5). For $n=8$ and $n=12$ the five frequencies and damping ratios are

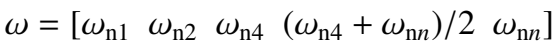

$$
\begin{aligned}
& \zeta=\left[\begin{array}{lllll}
0.01 & 0.01 & 0.012 & 0.02 & 0.05
\end{array}\right] \text {. }
\end{aligned}
$$

Figure 3 shows the equivalent Rayleigh damping fit using Equation (7) for the flexible, 12-story structure. The increased damping in the higher modes helps with numerical stability.

Once the coefficients $c_{p}$ are determined, the condensed damping matrix $\tilde{\mathbf{C}}$ is found from Equation (6). Now, the condensed equations of motion are

$$
\tilde{\mathbf{M}} \ddot{\mathbf{d}}_{\mathrm{p}}+\tilde{\mathbf{C}} \dot{\mathbf{d}}_{\mathrm{p}}+\tilde{\mathbf{K}} \mathbf{d}_{\mathrm{p}}=-\tilde{\mathbf{m}}_{\mathrm{u}}
$$

where vector $\tilde{\mathbf{m}}$ and matrices $\tilde{\mathbf{M}}$ and and $\tilde{\mathbf{K}}$ are given above.

\subsection{Orthotropic three-dimensional model}

In order to develop a 3D model from the planar frames thus far considered, assume that the building is orthotropic in the $x$ - and $y$-directions with identical structural properties [14]. The vectors $\mathbf{x}=\left[x_{1}, x_{2}, \ldots, x_{n}\right]^{\top}$ and $\mathbf{y}=\left[y_{1}, y_{2}, \ldots, y_{n}\right]^{\top}$ are the relative-to-the-ground displacements of the $i^{\text {th }}$ story in the $x$ - and $y$-directions, respectively. The uncoupled equations of motion are

$$
\begin{aligned}
\tilde{\mathbf{M}} \ddot{\mathbf{x}}+\tilde{\mathbf{C}} \dot{\mathbf{x}}+\tilde{\mathbf{K}} \mathbf{x}=-\tilde{\mathbf{m}} \ddot{u}_{\mathrm{g} x} \\
\tilde{\mathbf{M}} \ddot{\mathbf{y}}+\tilde{\mathbf{C}} \dot{\mathbf{y}}+\tilde{\mathbf{K}} \mathbf{y}=-\tilde{\mathbf{m}} \ddot{u}_{\mathrm{g} y}
\end{aligned}
$$

where $u_{\mathrm{g} x}$ and $u_{\mathrm{g} y}$ are the ground disturbances applied at the base of the structure. Coupling between the $x$ - and $y$-DOF is incorporated via a biaxial hysteresis model [25]. 


\subsection{Treatment of biaxial hysteresis}

The uncoupled (reduced) structural model (11) is coupled with the biaxial hysteresis model of Ref. [25]. The hysteresis model is a generalization of the Park-Wen model [26] — which is itself an extension of the uniaxial BoucWen model $[33,34]$ — that possesses an isotropic yield surface with an adjustable 'knee' from pre-yield to post-yield. The coupling procedure is described here. The deflection $\mathbf{x}$ and $\mathbf{y}$ relative to the ground are related to the inter-story deflections, denoted $\mathbf{u}_{x}=\left[u_{x 1}, \ldots, u_{x n}\right]^{\top}$ and $\mathbf{u}_{y}=\left[u_{y 1}, \ldots, u_{y n}\right]^{\top}$, respectively, as follows:

$$
\begin{aligned}
& \mathbf{x}=\mathbf{L} \mathbf{u}_{x} \Rightarrow \mathbf{u}_{x}=\mathbf{L}^{-1} \mathbf{x}, \\
& \mathbf{y}=\mathbf{L} \mathbf{u}_{y} \Rightarrow \mathbf{u}_{y}=\mathbf{L}^{-1} \mathbf{y},
\end{aligned}
$$

where $\mathbf{L}$ is the lower-triangular matrix,

$$
\mathbf{L}=\left[\begin{array}{cccc}
1 & 0 & \cdots & 0 \\
1 & 1 & \ddots & \vdots \\
\vdots & \ddots & \ddots & 0 \\
1 & \cdots & 1 & 1
\end{array}\right]
$$

The uncoupled equations of relative motion are

$$
\begin{aligned}
\tilde{\mathbf{M}}_{u} \ddot{\mathbf{u}}_{x}+\tilde{\mathbf{C}}_{u} \dot{\mathbf{u}}_{x}+\tilde{\mathbf{K}}_{u} \mathbf{u}_{x} & =-\tilde{\mathbf{m}}_{u} \ddot{u}_{\mathrm{g} x} \\
\tilde{\mathbf{M}}_{u} \ddot{\mathbf{u}}_{y}+\tilde{\mathbf{C}}_{u} \dot{\mathbf{u}}_{y}+\tilde{\mathbf{K}}_{u} \mathbf{u}_{y} & =-\tilde{\mathbf{m}}_{u} \ddot{u}_{\mathrm{g} y}
\end{aligned}
$$

where the matrices $\tilde{\mathbf{M}}_{u}=\mathbf{L}^{\top} \tilde{\mathbf{M}} \mathbf{L}, \tilde{\mathbf{C}}_{u}=\mathbf{L}^{\top} \tilde{\mathbf{C}} \mathbf{L}, \tilde{\mathbf{K}}_{u}=\mathbf{L}^{\top} \tilde{\mathbf{K}} \mathbf{L}$, and $\tilde{\mathbf{m}}_{u}=\mathbf{L}^{\top} \tilde{\mathbf{m}}$.

In order to incorporate inelastic behavior we replace the elastic inter-story forces with hysteretic forces,

$$
\begin{aligned}
\tilde{\mathbf{K}}_{u} \mathbf{u}_{x} & \rightarrow \kappa \tilde{\mathbf{K}}_{u} \mathbf{u}_{x}+(1-\kappa) \tilde{\mathbf{K}}_{u} \mathbf{z}_{x} \\
\tilde{\mathbf{K}}_{u} \mathbf{u}_{y} & \rightarrow \kappa \tilde{\mathbf{K}}_{u} \mathbf{u}_{y}+(1-\kappa) \tilde{\mathbf{K}}_{u} \mathbf{z}_{y}
\end{aligned}
$$

in which $\kappa$ is the ratio of the post-yield stiffness to pre-yield (elastic) stiffness. The auxiliary variables $\mathbf{z}_{x}=\left[z_{x 1}, \ldots, z_{x n}\right]^{\top}$ and $\mathbf{z}_{y}=\left[z_{y 1}, \ldots, z_{y n}\right]^{\top}$ are the isotropic hysteretic displacements, which are given by the generalized hysteresis model [25]:

$$
\begin{aligned}
\dot{\mathbf{z}}_{x} & =\dot{\mathbf{u}}_{x}-\mathbf{z}_{x} \circ \mathbf{b} \\
\dot{\mathbf{z}}_{y} & =\dot{\mathbf{u}}_{y}-\mathbf{z}_{y} \circ \mathbf{b}
\end{aligned}
$$

where the operator "o" is the element-wise multiplication of two vectors; and $\mathbf{b}=\left[b_{1}, \ldots, b_{n}\right]^{\top}$ is the biaxialinteraction vector where

$$
b_{i} \equiv b_{i}\left(z_{x i}, z_{y i}, \dot{u}_{x i}, \dot{u}_{y i}\right)=\left(\beta_{i}\left|\dot{u}_{x i} z_{x i}\right|+\gamma_{i} \dot{u}_{x i} z_{x i}+\beta_{i}\left|\dot{u}_{y i} z_{y i}\right|+\gamma_{i} \dot{u}_{y i} z_{y i}\right) \times\left(z_{x i}^{2}+z_{y i}^{2}\right)^{\frac{\eta_{i}-2}{2}} .
$$




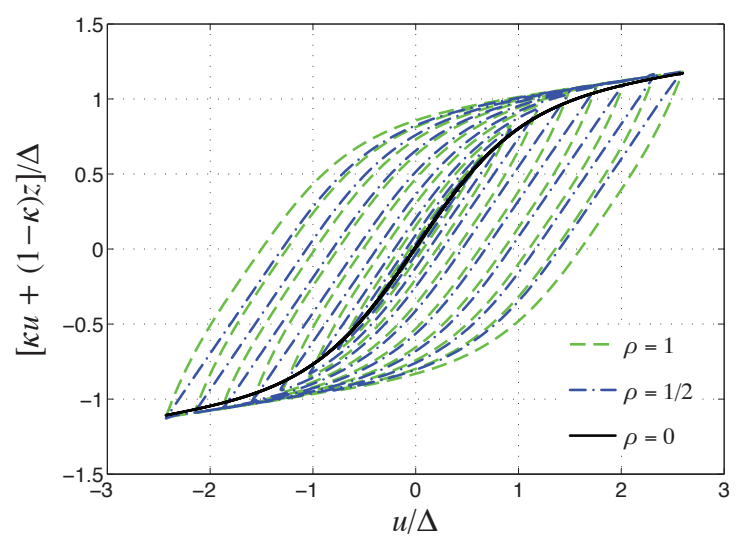

Figure 4: Representative hysteresis loops for $\kappa=0.1$ and $\eta=2$.

The biaxial hysteretic behavior at the $i^{\text {th }}$ story is governed by the parameters $\eta_{i}, \beta_{i}$, and $\gamma_{i}$, independent of the other stories. The parameter $\eta_{i}$ governs the smoothness of the transition from the linear to the nonlinear range [35], effectively adjusting the 'knee' of the hysteresis loop. The parameters $\beta_{i}$ and $\gamma_{i}$ govern the isotropic yield displacement $\Delta_{i}$ in the $i^{\text {th }}$ story as follows:

$$
\Delta_{i}=\left(\beta_{i}+\gamma_{i}\right)^{-\frac{1}{\eta_{i}}}
$$

Conversely, if the yield displacement $\Delta_{i}$ is prescribed, then the hysteresis parameters are

$$
\beta_{i}=\frac{\rho_{i}}{\Delta_{i}^{\eta_{i}}} \text { and } \gamma_{i}=\frac{1-\rho_{i}}{\Delta_{i}^{\eta_{i}}}
$$

where $0 \leq \rho_{i} \leq 1$. By varying $\rho_{i}$, the shape hysteresis loop changes, as illustrated in Fig. 4 .

The hysteretic restoring forces (15) are substituted into the uncoupled equations of motion (14):

$$
\begin{array}{r}
\tilde{\mathbf{M}}_{u} \ddot{\mathbf{u}}_{x}+\tilde{\mathbf{C}}_{u} \dot{\mathbf{u}}_{x}+\kappa \tilde{\mathbf{K}}_{u} \mathbf{u}_{x}+(1-\kappa) \tilde{\mathbf{K}}_{u} \mathbf{z}_{x}=-\tilde{\mathbf{m}}_{u} \ddot{u}_{\mathrm{g} x} \\
\tilde{\mathbf{M}}_{u} \ddot{\mathbf{u}}_{y}+\tilde{\mathbf{C}}_{u} \dot{\mathbf{u}}_{y}+\kappa \tilde{\mathbf{K}}_{u} \mathbf{u}_{y}+(1-\kappa) \tilde{\mathbf{K}}_{u} \mathbf{z}_{y}=-\tilde{\mathbf{m}}_{u} \ddot{u}_{\mathrm{g} y}
\end{array}
$$

Premultiply Equation (19) by $\mathbf{L}^{-\boldsymbol{T}}$ and substituting the expressions (12) for $\mathbf{u}_{x}$ and $\mathbf{u}_{y}$, the equations of motion are transformed back to absolute (relative-to-the-ground) coordinates:

$$
\begin{aligned}
\tilde{\mathbf{M}} \ddot{\mathbf{x}}+\tilde{\mathbf{C}} \dot{\mathbf{x}}+\kappa \tilde{\mathbf{K}} \mathbf{x}+(1-\kappa) \tilde{\mathbf{K}} \mathbf{L} \mathbf{z}_{x}=-\tilde{\mathbf{m}} \ddot{u}_{\mathrm{g} x} \\
\tilde{\mathbf{M}} \ddot{\mathbf{y}}+\tilde{\mathbf{C}} \dot{\mathbf{x}}+\kappa \tilde{\mathbf{K}} \mathbf{y}+(1-\kappa) \tilde{\mathbf{K}} \mathbf{L} \mathbf{z}_{y}=-\tilde{\mathbf{m}} \ddot{u}_{\mathrm{g} y}
\end{aligned}
$$

Likewise for the hysteretic coordinates:

$$
\begin{aligned}
\dot{\mathbf{z}}_{x} & =\mathbf{L}^{-1} \dot{\mathbf{x}}-\mathbf{z}_{x} \circ \mathbf{b} \\
\dot{\mathbf{z}}_{y} & =\mathbf{L}^{-1} \dot{\mathbf{y}}-\mathbf{z}_{y} \circ \mathbf{b}
\end{aligned}
$$


where

$$
b_{1}=\left(\beta_{1}\left|\dot{x}_{1} z_{x 1}\right|-\gamma_{1} \dot{x}_{1} z_{x 1}-\beta_{1}\left|\dot{y}_{1} z_{y 1}\right|-\gamma_{1} \dot{y}_{1} z_{y 1}\right) \times\left(z_{x 1}^{2}+z_{y 1}^{2}\right)^{\frac{\eta_{1}-2}{2}},
$$

and for $i=2,3, \ldots, n$,

$$
b_{i}=\left[\beta_{i}\left|\left(\dot{x}_{i}-\dot{x}_{i-1}\right) z_{x i}\right|-\gamma_{i}\left(\dot{x}_{i}-\dot{x}_{i-1}\right) z_{x i}-\beta_{i}\left|\left(\dot{y}_{i}-\dot{y}_{i-1}\right) z_{y i}\right|-\gamma_{i}\left(\dot{y}_{i}-\dot{y}_{i-1}\right) z_{y i}\right] \times\left(z_{x i}^{2}+z_{y i}^{2}\right)^{\frac{\eta_{i}-2}{2}}
$$

Equations (20) and (21) can be written in state-space form, as follows:

$$
\begin{aligned}
& \dot{\mathbf{X}}(t)=\mathbf{A} \mathbf{X}(t)+\mathbf{B} \ddot{u}_{\mathrm{g} x}(t)-\mathbf{J}\left[\left(\mathbf{J}^{\top} \mathbf{X}(t)\right) \circ \mathbf{b}(\mathbf{X}(t), \mathbf{Y}(t))\right] \\
& \dot{\mathbf{Y}}(t)=\mathbf{A Y}(t)+\mathbf{B} \ddot{u}_{\mathrm{g} y}(t)-\mathbf{J}\left[\left(\mathbf{J}^{\top} \mathbf{Y}(t)\right) \circ \mathbf{b}(\mathbf{X}(t), \mathbf{Y}(t))\right]
\end{aligned}
$$

where the $3 n$-dimensional state vectors and system matrices are

$$
\mathbf{X}(t)=\left\{\begin{array}{c}
\mathbf{x}(t) \\
\dot{\mathbf{x}}(t) \\
\mathbf{z}_{x}(t)
\end{array}\right\}, \mathbf{Y}(t)=\left\{\begin{array}{c}
\mathbf{y}(t) \\
\dot{\mathbf{y}}(t) \\
\mathbf{z}_{y}(t)
\end{array}\right\}, \mathbf{A}=\left[\begin{array}{ccc}
\mathbf{0} & \mathbf{I} & \mathbf{0} \\
-\kappa \tilde{\mathbf{M}}^{-1} \tilde{\mathbf{K}} & -\tilde{\mathbf{M}}^{-1} \tilde{\mathbf{C}} & -(1-\kappa) \tilde{\mathbf{M}}^{-1} \tilde{\mathbf{K}} \mathbf{L} \\
\mathbf{0} & \mathbf{L}^{-1} & \mathbf{0}
\end{array}\right], \mathbf{B}=\left\{\begin{array}{c}
\mathbf{0} \\
-\tilde{\mathbf{M}}^{-1} \tilde{\mathbf{m}} \\
\mathbf{0}
\end{array}\right\} \mathbf{J}=\left[\begin{array}{l}
\mathbf{0} \\
\mathbf{0} \\
\mathbf{I}
\end{array}\right] .
$$

Note that the coupling between $x$ - and $y$-directional responses appears only in the biaxial hysteresis term $\mathbf{b}(\mathbf{X}(t), \mathbf{Y}(t))$.

\subsection{Model verification via pushover analyses}

Finally, to verify that the condensed hysteretic system behaves similarly to a complete inelastic model, static pushover curves [36] generated using EPFRAME [37] for the complete model (M, K) will be compared to quasi-static pushover curves for the hysteretic reduced model $(\tilde{\mathbf{M}}, \tilde{\mathbf{K}})$. The program EPframe returns the load-deflection relationships of elastic-plastic collapse analyses on planar frames.

Figure 5 shows the base shear versus the displacement ratio for the six buildings. The solid lines indicate the roof displacement ratio, $x_{n}$ normalized by the structure height; the dashed lines indicate the first-story displacement ratio $x_{1} / h_{1}$. Results of the quasistatic elastic, perfectly-plastic EPframe analyses are given by the blue lines with circles and squares indicating the formation of plastic hinges; beyond the largest displacement ratios, the structure collapses because the first-story possesses no additional elastic resistance.

Dynamic tests using the hysteretic reduced model are performed using linearly increasing base accelerations, $\ddot{u}_{g x}(t) \propto t$. The hysteresis parameters $\rho_{i}$ are taken to be uniform throughout the structure and equal to $\rho_{i}=\rho=1 / 2$. Three values of $\kappa$ are considered: $\kappa=0,0.1$, and 1 . For $\kappa=1$, the system behaves purely elastically, and in all cases, the black lines pass through the first-point of the EPFrame analysis. The case $\kappa=0$ was used to calibrate the model to the EPframe analysis. To tune the proposed model, the yield displacements $\Delta_{i}$ (Equation (18)) were determined such that a roughly equivalent failure load level was achieved as compared to the EPfrAmE-determined value. The following relationships were determined for the flexible and rigid structures:

$$
\Delta_{i}= \begin{cases}0.010 \times h_{i}: & \text { flexible } \\ 0.009 \times h_{i}: & \text { rigid }\end{cases}
$$


where $h_{i}$ is the $i^{\text {th }}$ inter-story height.

The knee-sharpness parameter was taken to be uniform throughout the structure and equal to $\eta_{i}=\eta \forall i$. Figure 6 shows the effect of changing $\eta$. As $\eta$ increases, the elastic and inelastic responses diverge at higher displacement ratios and base shears, and the transition form pre-yield to post-yield stiffness is less gradual. A value of $\eta=7$ was chosen such that the condensed model diverges from elastic behavior at roughly $0.7 \%$ drift ratio in the first-story, which is representative of actual structures. A value of $\kappa=0.1$ will be used in subsequent simulations to model strain-hardening effects that cannot be captured with an elastic, perfectly-plastic model

\section{Selected earthquake ground motions}

The performance of lightly- and heavily-damped RISs is examined for fifty bidirectional earthquake ground motion records: twenty-two far-field (FF), fourteen near-fault without a pulse (NFNP), and fourteen near-fault with a pulse (NFP). The ground motions used in this study are from the ATC-63 Project [38], whose primary objective is to create a methodology to determine seismic performance factors for inelastic, collapse-sensitive structures. The ATC63 project selected sets of ground motion records form the Pacific Earthquake Engineering Research Center Next Generation Attenuation (PEER-NGA) project database [39]. The selected records are classified into three categories (FF, NFNP, and NFP), which are divided so as to have roughly similar response and ground motion characteristics, e.g. magnitude $M>6.5$ crustal earthquakes with peak ground velocity PGV $>15 \mathrm{~cm} / \mathrm{s}$ and peak ground acceleration PGA $>0.3 \mathrm{~g}$. For the FF set, epicenter distance $>10 \mathrm{~km}$; for the NFNP and NFP sets, epicenter distance $\leq 10 \mathrm{~km}$.

Each set is normalized so each record in the set has the same PGV, in a square-root sum-of-squares (SRSS) sense. SRSS was chosen, instead of geometric mean (GM), because it provides a rotation-independent (objective) measure of PGV [40]. Each record was integrated via the trapezoidal rule, and the peak radial PGVs were calculated and tabulated. Tables 4, 5, and 6 give the ground motion statistics of the fifty ATC-63 ground motion records used in this study. For each category (FF, NFNP, NFP), the ground motions are normalized to two intensity levels, moderate and strong, which are categorized in Table 2. Additional details are provided in the ATC-63 project website [38].

Table 2: Scaled peak ground velocities (PGVs) of the selected moderate and strong ground motions.

\begin{tabular}{lccc}
\hline & \multicolumn{3}{c}{ Peak Ground Velocity (PGV) $[\mathrm{cm} / \mathrm{s}]$} \\
\cline { 2 - 4 } & Far-Field (FF) & Near-Fault w/o Pulse (NFNP) & Near-Fault w/ Pulse (NFP) \\
\hline Moderate & 16.5 & 26 & 40 \\
Strong & 33 & 52 & 80 \\
\hline
\end{tabular}


(a)

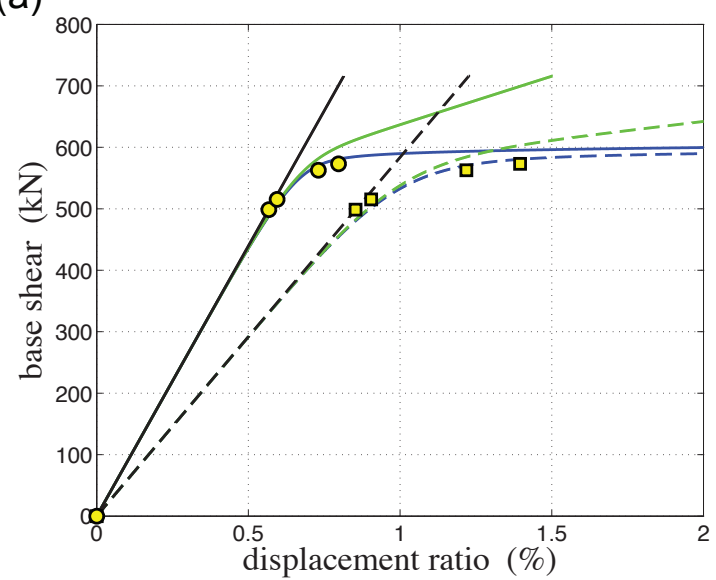

(c)

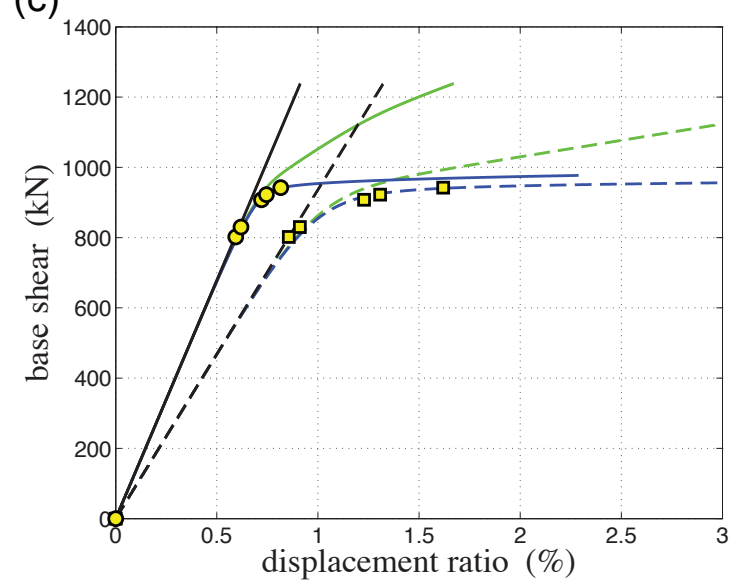

(e)

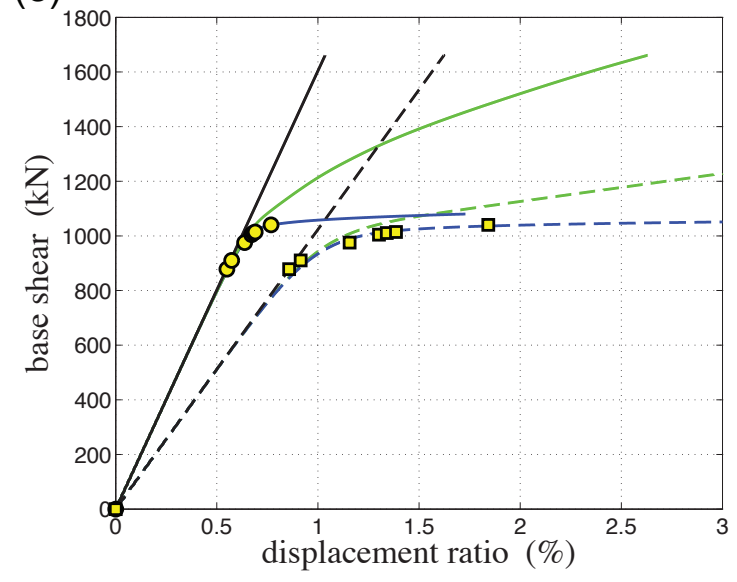

(b)

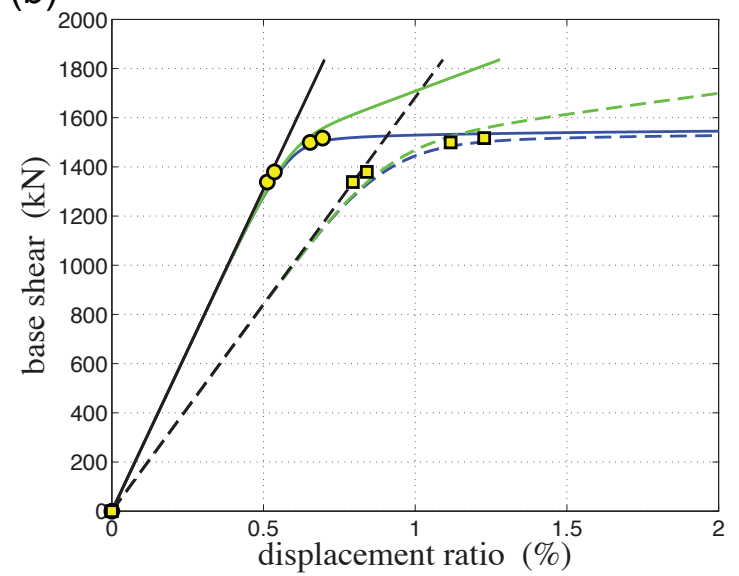

(d)

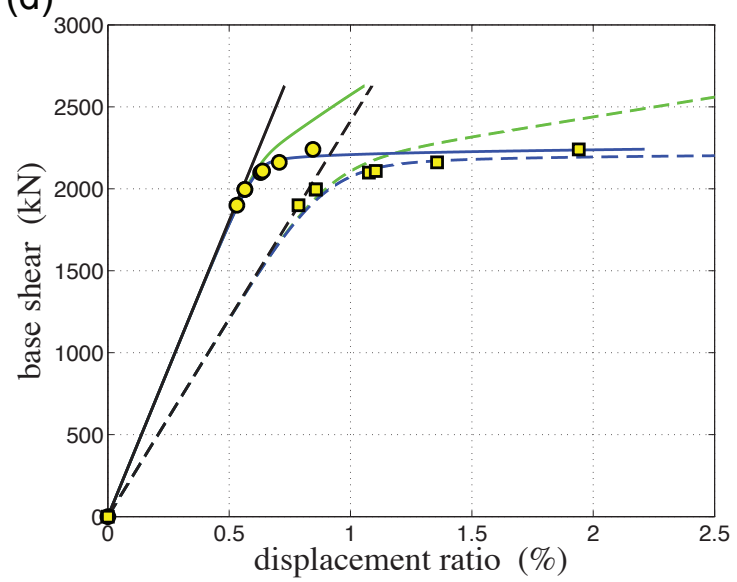

(f)

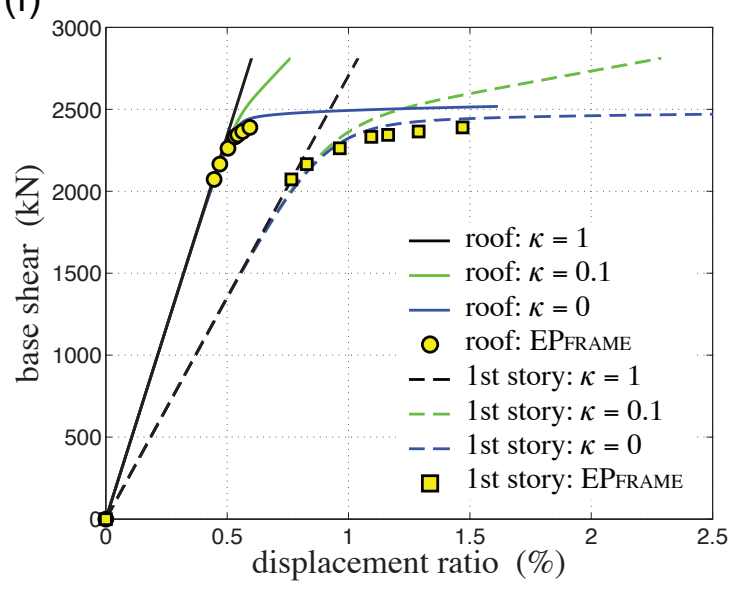

Figure 5: Base shear force versus roof (solid) and 1st-story (dashed) drift ratio for $\eta=7$ : (a) 4-story, flexible structure; (b) 4-story, rigid structure; (c) 8-story, flexible structure; (d) 8-story, rigid structure; (e) 12-story, flexible structure; (f) 12-story, rigid structure. 


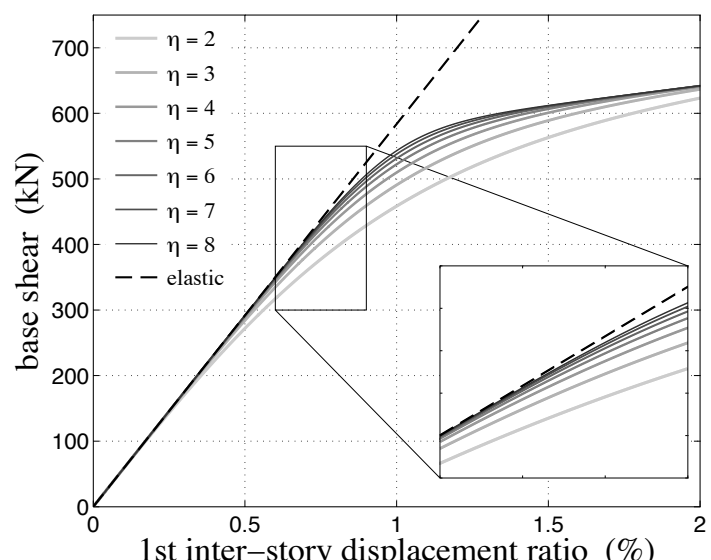

Figure 6: Base shear force versus 1st-story drift ratio for knee-sharpness parameter $\eta$ values of $2,3, \ldots, 8$ (from bottom to top) compared to elastic system (一): 4-story, flexible structure.

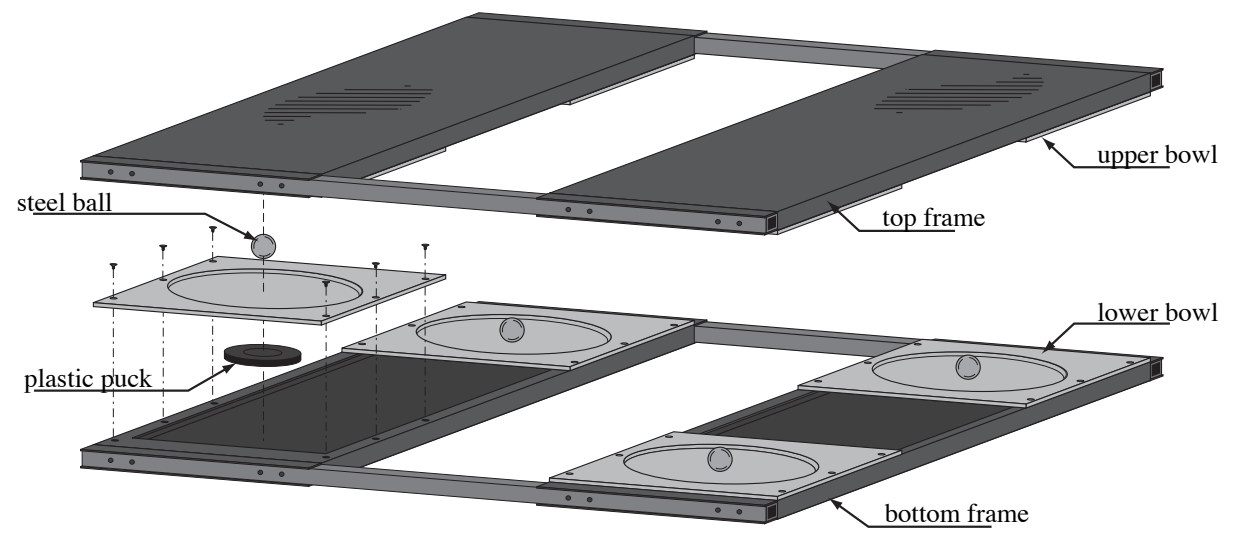

Figure 7: Exploded view of a lightly-damped rolling isolation system.

\section{Assessment of the seismic performance of rolling isolation systems}

An illustration of the RIS to be analyzed in this article is shown in Figure 7. The system comprises a pair of rectangular frames, four pairs of shallow bowls, and four rigid steel balls. The object resting on the top frame is isolated from the floor motion applied to the bottom frame through a rolling pendulum mechanism. The bottom and top frames contain four concave-up bowls and four concave-down bowls, respectively, at their corners. Four steel balls roll between the lower and upper bowls (Figure 7) allowing for the top frame to displace with respect to the bottom frame. The bowl profiles of the system studied in this paper are approximately quadratic near the bowl centers and are approximately cone-shaped at larger distances from the centers [19]. These bowl profile regimes dictate the restoring forces of the system. At the edge of the each bowl's rolling surface, a lip acts as a stiff limit on the ball's displacement. The isolation system's displacement capacity is determined by the contact of the balls with the bowl 
lips.

Lightly-damped RISs represent a popular method for the seismic protection of fragile objects [41], and these systems can perform extremely well when their displacement demands are small $(<10-15 \mathrm{~cm})[14,42]$. When the isolator's displacement capacity is insufficient to meet the demands of a disturbance, the performance of the isolator is diminished due to impacts, giving rise to potentially high acceleration responses in isolated objects. An RIS designed for strong (infrequent) floor motions would require either (i) a larger displacement capacity, or (ii) supplemental damping to reduce displacement demands. Two methods for adding damping to RISs have been investigated: (i) encasing the balls with a damping material (e.g. rubber) [43] or (ii) bonding viscoelastic layers to the counter-facing surfaces [44]. Both approaches act to increase the rolling resistance and thus increase energy dissipation, decrease isolator displacements, and improve performance over lightly-damped RISs. The latter approach, referred to as a heavily-damped RIS, is considered in the present study [27].

\subsection{Response analysis}

The seismic responses of lightly- and heavily-damped RISs are determined by performing a transient dynamic analyses of each isolation system and its supporting building. In simulating the response of the rolling isolation system to floor motions, it is assumed that the motion of the RIS has a negligible effect on the motion of the floor. In the context of assessing the performance of the isolation system, this is a conservative assumption [45]. (If significant energy can be transmitted from the isolation system to the structural frame, then the responses of the isolation system will be lower.) This assumption is warranted if either of two conditions hold: (i) the isolated mass is small compared to that of the floor, or (ii) the isolation system period does not coincide with any of the structural periods. In the scenario considered in this paper, condition (i) holds across all models. The issue of frequency matching is addressed in the following sections. Furthermore, the separation of the simulation of the building floor responses and the isolation system responses provides a more modular framework for assessing these systems.

The building and RIS responses are modeled as uncoupled, ignoring the dynamic interaction between building and nonstructural components. Such an analysis leads to substantial savings in computational costs and also avoids numerical difficulties that could arise in the coupled system due to large differences in the properties of the two systems [45]. Furthermore, uncoupled analyses are slightly more conservative than coupled analyses when the ratio of the component mass to the floor mass is small $(<1 \%)$ and the natural frequency of the component are close to a modal frequency of the structure. For cases in which no modal frequency matches the component frequency, the uncouple analysis is very accurate.

The fifty moderate and the fifty strong bidirectional earthquake ground motion records (Section 4) are applied to the six hysteretic reduced structural models (Sections 2 and 3). The total acceleration floor responses at three heights - 1st story, mid-height, and roof, as indicated in Figure 2 - are evaluated and then applied to the validated models for lightly- and heavily-damped RISs $[19,27]$. The peak relative displacement $\left(d_{\mathrm{R}}^{\max }\right)$ and the peak total acceleration $\left(a_{\mathrm{T}}^{\max }\right)$ of the RISs are recorded. 
A total of six hundred simulations are performed which can be thought of as a sampling of representative response scenarios for RIS installations. As such, empirical peak-response CDFs are constructed for the various scenarios. The definition of the distribution function is $F(x)=\mathbb{P}(X \leq x)$. An empirically estimate of the CDF is

$$
F(x)=\frac{\# \text { of sample values } \leq x}{N}=\frac{1}{N} \sum_{i=1}^{N} 1_{x_{i} \leq x}
$$

where $1_{A}$ is the indicator of event $A$, and $N$ is the total number of samples (simulations).

For the six structures, Figures 8-13 present the peak-displacement empirical CDFs, $F\left(d_{\mathrm{R}}^{\max }\right)$, under (a-b) FF, (c-d) NFNP, and (e-f) NFP ground motions at the two loading intensities - (a,c,e) moderate and (b,d,f) strong. The CDFs are plotted on Normal distribution axes. It is important to note that the peak relative displacement $d_{\mathrm{R}}^{\max }$ is bounded below by zero and above by the bowl diameter (approximately $22 \mathrm{~cm}$ ). For values of $d_{\mathrm{R}}^{\max }>22 \mathrm{~cm}$, the steel balls impacts with the bowl lip, acting as a hard displacement limit.

From these figures, it may be observed that, in general, the peak displacement responses are smaller at lower attachment points. That is, the 1st story CDFs exhibit support at lower values of $d_{\mathrm{R}}^{\max }$ than the mid-height CDFs, which are themselves lower than the roof CDFs. This effect is taken into consideration in non-structural component design codes [46, 47]. For example, the SEI/ASCE 7-10 provisions [47] on non-structural component demands defines a linear variation of peak floor acceleration up the height of the building. The equipment design spectral acceleration is proportional to the floor height coefficient $(1+2 z / h)$, where $z / h$ is the component attachment height $(z)$ over the height $(h)$ of the building. For the three attachment locations in the three structures, the floor height coefficient are given in Table 5.1. For the 4-, 8- and 12-story structures, the demands at the 1st story are 56, 45 and 41 percent of the demands at the roof. Figures 8-13 demonstrate similar dependence on the equipment attachment height. In a majority of the structures and load intensities, when the RIS is attached at the 1st story, there is greater than a 90 percent probability that the a peak displacement will not exceed $20 \mathrm{~cm}$. Whereas, at higher attachment points (mid-height and roof), nearly all the the cases exhibit peak displacements in excess of $20 \mathrm{~cm}$, especially under strong ground motions.

As demonstrated in Ref [27], when supplemental damping is included in an RIS, the displacement demands of the RIS are decreased, improving the performance and better protecting the isolated object. In all cases, the distribution functions for the lightly-damped RIS fall to the left (lower peak displacements) than those for the heavily-damped

Table 3: Floor height coefficients.

\begin{tabular}{lccc}
\hline & \multicolumn{3}{l}{ Equipment attachment location } \\
\cline { 2 - 4 } & 1st story & mid-height & roof \\
\hline 4-story & 1.67 & 2.11 & 3.00 \\
8-story & 1.35 & 2.06 & 3.00 \\
12-story & 1.24 & 2.04 & 3.00 \\
\hline
\end{tabular}


RIS. Therefore, heavily-damped RISs outperform the lightly-damped RISs, in terms of peak displacement.

Figures 14 and 15 show the peak-acceleration empirical CDFs, $F\left(a_{\mathrm{T}}^{\max }\right)$, for stiff and rigid structures, respectively, subject to the suite of far-field ground motions. The CDFs are plotted on log-Normal axes. Due to the cone-shaped profile of the bowls (see Ref. [27]), the peak acceleration in the absence of impacts is limited by the bowl's slope and damping: $0.13 g$ in the lighlty-damped RIS, and $0.20 g$ in the heavily-damped RIS (because of the additional rolling resistance). These limits are exhibited in Figures 14 and 15 by vertically aligned points in the CDF. A histogram (or probability density function) of the peak acceleration response would have a narrow mode at these acceleration values. However, in cases with impacts, the peak total accelerations are very high, up to $20 \mathrm{~g}$. In such cases, the isolation system fails to perform properly, and the isolated object may topple or otherwise fail.

One can also observe from Figures 14 and 15 that structures with natural periods close to the RIS natural period (approximately $1.2 \mathrm{~s}$ ) tend to produce larger peak isolation displacements. Three of the structures - 4-story, flexible; 8-story, rigid; and 12-story, rigid — produce especially large acceleration responses in the isolated system. The first natural periods $\left(1 / f_{\mathrm{n} 1}\right)$ of these structures are, respectively, $1.27,1.18$, and $1.54 \mathrm{~s}$, which are close to the RIS natural period. Whereas, the other structures - 4-story, rigid; 8-story, flexible; and 12-story, flexible — do not have natural periods near the RIS natural period. These structures have first natural periods of $0.73,1.92$, and $2.63 \mathrm{~s}$, respectively. The 8- and 12-story, flexible structures have second natural periods $\left(1 / f_{\mathrm{n} 2}\right)$ of 0.68 and $0.93 \mathrm{~s}$, respectively. Therefore, the application of isolation systems with periods that are close to the structure's period should be avoided. Future work will address the means to tailor the period, damping, and displacement capacity of rolling isolation systems to the supporting structure's natural periods and the location of the isolation system within the structure.

\subsection{RIS installation guidelines}

The following installation guidelines are supported by the foregoing time-history analyses and peak-response empirical CDFs for the RISs studied herein:

- As suggested by non-structural component design provisions [47], the floor accelerations increase in the upper floors of the buildings, and hence the RIS displacement and acceleration responses increase in the upper floors. Therefore, one should locate the isolated components as close to the first floor as possible. The floor level of the installation is not as important for low-rise structures (e.g. 4 stories).

- The peak acceleration response of an RIS may increase when the supporting building possesses a (first or higher) mode that is close to the RIS's natural period. The particular RIS analyzed in this study responds more strongly to motions with periods in the $1.1 \mathrm{~s}$ to $1.6 \mathrm{~s}$ range. RISs with longer natural periods should perform well in such installations.

- The displacement demand on heavily-damped RISs are significantly lower than on lightly-damped RISs, which was suggested previously [27]. Supplemental damping via rubber rolling surfaces is capable of improving the performance of RISs for high-intensity motions. 
Installations adhering to these recommendations are not likely to experience isolation displacement demands in excess of $22 \mathrm{~cm}$ for ground motions with a PGV up to $50 \mathrm{~cm} / \mathrm{s}$ for heavily-damped isolation systems, and a PGV up to $25 \mathrm{~cm} / \mathrm{s}$ for lightly-damped RISs.

It is worthwhile to note that, because these analyses were performed using an uncoupled structure-isolator approach, the calculated peak responses are conservative. Thus, the suggested bounds on the structure's fundamental period could be conservative as well.

\section{Concluding remarks}

The purpose of this paper has been to utilize the experimentally-validated predictive models derived in Ref. [27] to assess the performance of lightly- and heavily-damped RISs within inelastic seismically-excited building structures. In an attempt to study a range of potential installations, we select six code-designed structures of varying height and stiffnesses from Ref. [28], which are representative of existing buildings in California. However, unlike the analysis performed in that paper and other studies in the literature, the bidirectional horizontal responses of the structures, instead of planar responses, are considered here. A new approach to model reduction for hysteretic systems was presented, in which the orthogonal, inter-story responses of the structure are coupled by a biaxial hysteretic model [25].

The study comprises the time-history analyses of lightly- and heavily-damped RISs alternatively attached to the six structures. Each of the analyses is performed under an ensemble of fifty scaled earthquake ground motions classified into three categories: Far-Field (FF), Near-Fault without a Pulse (NFNP), and Near-Fault with a Pulse (NFP). Two intensities of shaking are considered, and empirical CDFs of the peak displacement and the peak acceleration responses are presented. From these CDFs, installation recommendations for the particular RISs considered in this study are suggested, which should be heeded if RISs are being considered for the protection of vital objects. In summary, the heavily-damped RIS outperforms the lightly-damped RIS over all the cases considered, structures with fundamental periods tuned to the natural period of the RIS should be avoided, and the isolated components should be located as close to the ground as possible.

The highly-damped RIS system studied in this project responded with peak accelerations of $0.2 g$, as compared to the lightly-damped system with a peak acceleration of approximately $0.13 \mathrm{~g}$ - for all responses that did not involve an impact at a displacement of $22 \mathrm{~cm}$. Even highly-damped RIS's located on the 1st story will reach their displacement capacities with a 25 percent to 30 percent probability when responding to ground motions with $P G V=33 \mathrm{~cm} / \mathrm{s}$ if the natural period of the structure is close to that of the isolation system. This shows that RIS system can be sensitive to period-matching effects even when installed in the lower stories.

Nonetheless, the RIS need not have a natural period longer than the fundamental period of the structure to perform well. The highly-damped RIS systems situated on the first story of structures with periods longer than the RIS period have a negligible probability of reaching their displacement capacities even for ground motions with PGV up to 
approximately $50 \mathrm{~cm} / \mathrm{s}$.

Of the cases analyzed in this study, for installations at the top level, only the heavily-damped RIS has an impact probability less than 20 percent when installed in a short-period structure (period $=0.7 \mathrm{~s}$ ) and shaken with ground motions with PGV of $16 \mathrm{~cm} / \mathrm{s}$.

These observations indicate that a means to tailor RIS systems to the dynamic environment of their installation (period and intensity of floor motion) will enhance the robustness of these simple isolation systems.

\subsection{Future research directions}

Future research in this area, which will have the greatest impact potential, should focus on the following areas:

- Preliminary results show that the model reduction method presented in this paper is effective in replicating the quasi-static response of hysteretic structures, with considerable savings in computational effort. A more comprehensive analysis is needed in order to quantify the performance of the method.

- The foregoing conclusions are obviously valid only for the building types, RISs, and ground motions herein considered. Additional studies need to be conducted under more general conditions (e.g., with different building types and different ground motions) to verify these conclusions.

- More work is warranted in the study of tailoring the design of RISs to the dynamic environment of their installation. This study showed that the heavily-damped RIS outperforms the lightly-damped RIS, at the expense of increasing peak accelerations in the absence of impacts. Thus, for design purposes, different levels of supplemental damping in the RIS should be investigated so as to optimize the isolation system's performance. Additionally, the bowl profile may be tailored to influence the restoring forces, and thus the response; to avoid needing to re-design the bowl shape for every installation (for which there are infinite possibilities), standardized shapes described by a general shape parameterizations should be considered to allow for incorporation in to codes and standards. These results will be particularly useful to designers and will have an immediate impact on design implications.

\section{Acknowledgments}

Financial support for this project was provided by the Civilian Research and Development Foundation for the Independent States of the Former Soviet Union (CRDF) under Award No. MG1-2319-CH-02 and by the National Science Foundation under Grant Nos. NSF-CMMI-0704959 (NEES Research), NSF-CMS-0402490 (NEES Operations), and NSF-CMMI-0900324. This support is greatly appreciated. 


\section{References}

[1] E. Cosenza, L. Di Sarno, G. Maddaloni, G. Magluilo, C. Petrone, A. Prota, Shake table tests for the seismic fragility evaluation of hospital rooms, Earthquake Engineering and Structural Dynamicsdoi :10.1002/eqe. 2456.

[2] C. Alhan, F. Şahin, Protecting vibration-sensitive contents: an investigation of floor accelerations in seismically isolated buildings, Bulletin of Earthquake Engineering 9 (2011) 1203-1226. doi:10.1007/s10518-010-9236-0.

[3] G. Mosqueda, R. Retamales, A. Filliatrault, A. Reinhorn, Testing facility for experimental evaluation of non-structural components under full-scale floor motions, The Structural Design of Tall and Special Buildings 18 (2009) 387-404. doi : 10.1002/tal.441.

[4] M. C. Comerio, PEER testbed study on a laboratory building: exercising seismic performance assessement, Tech. Rep. Report No. PEER2005/12, Pacific Earthquake Engineering Research Center, University of California, Berkeley (2005).

[5] R. A. Ibrahim, Recent advances in nonlinear passive vibration isolators, Journal of Sound and Vibration 314 (2008) 371-452. doi : 10 . 1016/ j.jsv.2008.01.014.

[6] W. D. Iwan, The earthquake design and analysis of equipment isolation systems, Earthquake Engineering and Structural Dynamics 6(12) (1978) 523-534. doi:10.1002/eqe.4290060602.

[7] M. C. Constantinou, A. S. Mokha, A. S. Reinhorn, Teflon bearings in base isolation II: Modeling, Journal of Structural Engineering 116 (2) (1990) 455-474. doi:10.1061/(ASCE) 0733-9445(1990) 116:2(455).

[8] W. H. Robinson, Lead rubber hysteretic bearings suitable for protecting structures during earthquakes, Earthquake Engineering and Structural Dynamics 10 (1982) 593-604.

[9] M. Ismail, J. Rodellar, F. Ikhouane, An innovative isolation bearing for motion-sensitive equipment, Journal of Sound and Vibration 326 (2009) 503-521. doi:10.1016/j.jsv.2009.06.022.

[10] D. Konstantinidis, F. Nikfar, Seismic response of sliding equipment and contents in base-isolated buildings subjected to broadband ground motions, Earthquake Engineering and Structural Dynamicsdoi : 10.1002/eqe. 2490.

[11] R. Y. Tan, Y. T. Lung, Dynamic response of equipment in structures with consideration of tuning effect, Engineering Structures 14 (1992) 300-308. doi:10.1016/0141-0296(92)90043-P.

[12] S. Furukawa, E. Sato, Y. Shi, T. C. Becker, M. Nakashima, Full-scale shaking table test of a base-isolated medical facility subjected to vertical motions, Earthquake Engineering and Structural Dynamics 42 (2013) 1931-1949. doi : 10.1002/eqe.2305.

[13] G. Jia, I. Gidaris, A. A. Taflanidis, G. P. Mavroeidis, Reliability-based assessement/design of floor isolation systems, Engineering Structures 78 (2014) 41-56. doi : 10.1016/j . engstruct. 2014.07 .031$.

[14] C. Alhan, H. P. Gavin, Reliability of base isolation for the protection of critical equipment from earthquake hazards, Engineering Structures 27 (2005) 1435-1449. doi:10.1016/j.engstruct.2005.04.007.

[15] L.-Y. Lu, T.-Y. Lee, S.-Y. Juang, S.-W. Yeh, Polynomial friction pendulum isolators (PFPIs) for building floor isolation: An experimental and theoretical study, Engineering Structures 56 (2013) 970-982. doi:10.1016/j.engstruct.2013.06.016.

[16] S. Liu, G. P. Warn, Seismic performance and sensitivity of floor isolation systems in steel plate shear wall structures, Engineering Structures 42 (2012) 115-126. doi:10.1016/j.engstruct.2012.04.015.

[17] G. F. Demetriades, M. C. Constantinou, A. M. Reinhorn, Study of wire rope systems for seismic protection of equipment in buildings, Engineering Structures 15 (1993) 321-334. doi:10.1016/0141-0296(93)90036-4.

[18] A. Contento, A. Di Egidio, On the use of base isolation for the protection of rigid bodies placed on a multi-storey frame under seismic excitation, Engineering Structures 62-63 (2014) 1-10. doi : 10.1016/j . engstruct.2014.01.019.

[19] P. S. Harvey Jr, H. P. Gavin, The nonholonomic and chaotic nature of a rolling isolation system, Journal of Sound and Vibration 332 (2013) 3535-3551. doi:10.1016/j.jsv.2013.01.036.

[20] F. Bamer, C. Bucher, Application of the proper orthogonal decomposition for linear and nonlinear structures under transient excitations, Acta Mechanica 223 (2012) 2549-2563. doi:10.1007/s00707-012-0726-9.

[21] R. Kappagantu, B. F. Feeny, An “optimal” modal reduction of a system with frictional excitation, Journal of Sound and Vibration 224 (1999) 863-877. doi:10.1006/jsvi.1999.2165. 
[22] L. F. Geschwindner, Non-linear dynamic analysis of modal superposition, Journal of Structural Division-ASCE 107 (1981) 2325-2336.

[23] R. Villaverde, M. M. Hanna, Efficient mode superposition algorithm for seismic analysis of nonlinear structures, Earthquake Engineering and Structural Dynamics 21 (1992) 849-858. doi:10.1002/eqe.4290211002.

[24] M. Paz, Dynamic condensation, AIAA Journal 22 (1985) 724-727.

[25] P. S. Harvey Jr, H. P. Gavin, Truly isotropic biaxial hysteresis with arbitrary knee sharpness, Earthquake Engineering and Structural Dynamics 43 (2014) 2051-2057. doi:10.1002/eqe. 2436.

[26] Y. J. Park, Y. K. Wen, A. H.-S. Ang, Random vibration of hysteretic systems under bi-directional ground motion, Earthquake Engineering and Structural Dynamics 14 (1986) 543-557. doi :10.1002/eqe.4290140405.

[27] P. S. Harvey Jr, G.-P. Zéhil, H. P. Gavin, Experimental validation of simplified models for rolling isolation systems, Earthquake Engineering and Structural Dynamics 43 (2014) 1067-1088. doi:10.1002/eqe. 2387.

[28] R. P. Santa-Ana, E. Miranda, Strength reduction factors for multi-degree-of-freedom systems, in: Proc. 12th World Conf. on Earthquake Engineering, Auckland, New Zealand, 2000.

[29] S. R. Chaudhuri, R. Villaverde, Effect of building nonlearity on seismic response of nonstructural components: A parametric study, Journal of Structural Engineering 134 (2008) 661-670. doi:10.1061/(ASCE) 0733-9445(2008) 134:4(661).

[30] H. P. Gavin, Frame3DD: Static and Dynamic Structural Analysis of 2D and 3D Frames.

URL http://frame3dd. sourceforge.net/

[31] R. J. Guyan, Reduction of stiffness and mass matrices, AIAA Journal 3 (1965) 380.

[32] R. W. Clough, J. Penzien, Dynamics of Structures, 2nd Edition, Computers and Structures, Inc., 2003.

[33] R. Bouc, Forced vibration of mechanical systems with hysteresis, in: Proceedings of the Fourth Conference on Nonlinear Oscillation, Prague, Czechoslovakia, 1967.

[34] Y.-K. Wen, Method for random vibration of hysteretic systems, Journal of Engineering Mechanics 102 (1976) $249-263$.

[35] C. W. Wong, Y. Q. Ni, J. M. Ko, Stead-state oscillation of hysteretic differential model II: Performance analysis, Journal of Engineering Mechanics 120 (11) (1994) 2299-2325. doi:10.1061/(ASCE) 0733-9399(1994) 120:11(2271).

[36] B. G. Neal, The plastic method of structural analysis, 3rd Edition, Chapman \& Hall, New York, 1977.

[37] H. Lee, EPframe: Elastic Plastic Analysis of a Plane Frame (1986).

URL http://nees.org/tools/epframe/

[38] Applied Technology Council, Quantification of building seismic performance factors.

URL https : //www . atcouncil .org/Projects/atc-63-project.html

[39] Pacific Earthquake Engineering Research Center, Next Generation Attenuation Database (2005).

URL http://peer. berkeley.edu/nga/

[40] J. P. Stewart, N. A. Abrahamson, G. M. Atkinson, J. W. Baker, D. M. Boore, Y. Bozorgnia, K. W. Campbell, C. D. Comartin, I. M. Idriss, M. Lew, M. Mehrain, J. P. Moehle, F. Naeim, T. A. Sabol, Representation of bidirectional ground motions for design spectra in building codes, Earthquake Spectra 27 (2011) 927-937. doi:10.1193/1.3608001.

[41] Kemeney, US 7,784,225 B2, Isolation Platform (2010).

[42] H. P. Gavin, A. Zaicenco, Performance and reliability of semi-active equipment isolation, Journal of Sound and Vibration 306 (2007) 74-90. doi:10.1016/j.jsv.2007.05.039.

[43] C. S. Tsai, Y.-C. Lin, W.-S. Chen, H. C. Su, Tri-directional shaking table tests of vibration sensitive equipment with static dynamics interchangeable-ball pendulum system, Earthquake Engineering and Engineering Vibration 9 (2010) 103-112. doi:10.1007/ s11803-010-9009-4.

[44] L. Guerreiro, J. Azevedo, A. H. Muhr, Seismic tests and numerical modeling of a rolling-ball isolation system, Journal of Earthquake Engineering 11(1) (2007) 49-66. doi : 10.1080/13632460601123172.

[45] Y. Chen, T. T. Soong, Seismic response of secondary systems, Engineering Structures 10 (1988) 218-228. doi:10.1016/0141-0296 (88) 90043-0. 
[46] NZS 1170.5:2004, Structural Design Actions Part 5: Earthquake Actions - New Zealand, Standards New Zealand, New Zealand, 2004.

[47] ASCE/SEI 7-10, Minimum design loads for buildings and other structures, Structural Engineering Institute of ASCE, Reston, VA, 2010. 

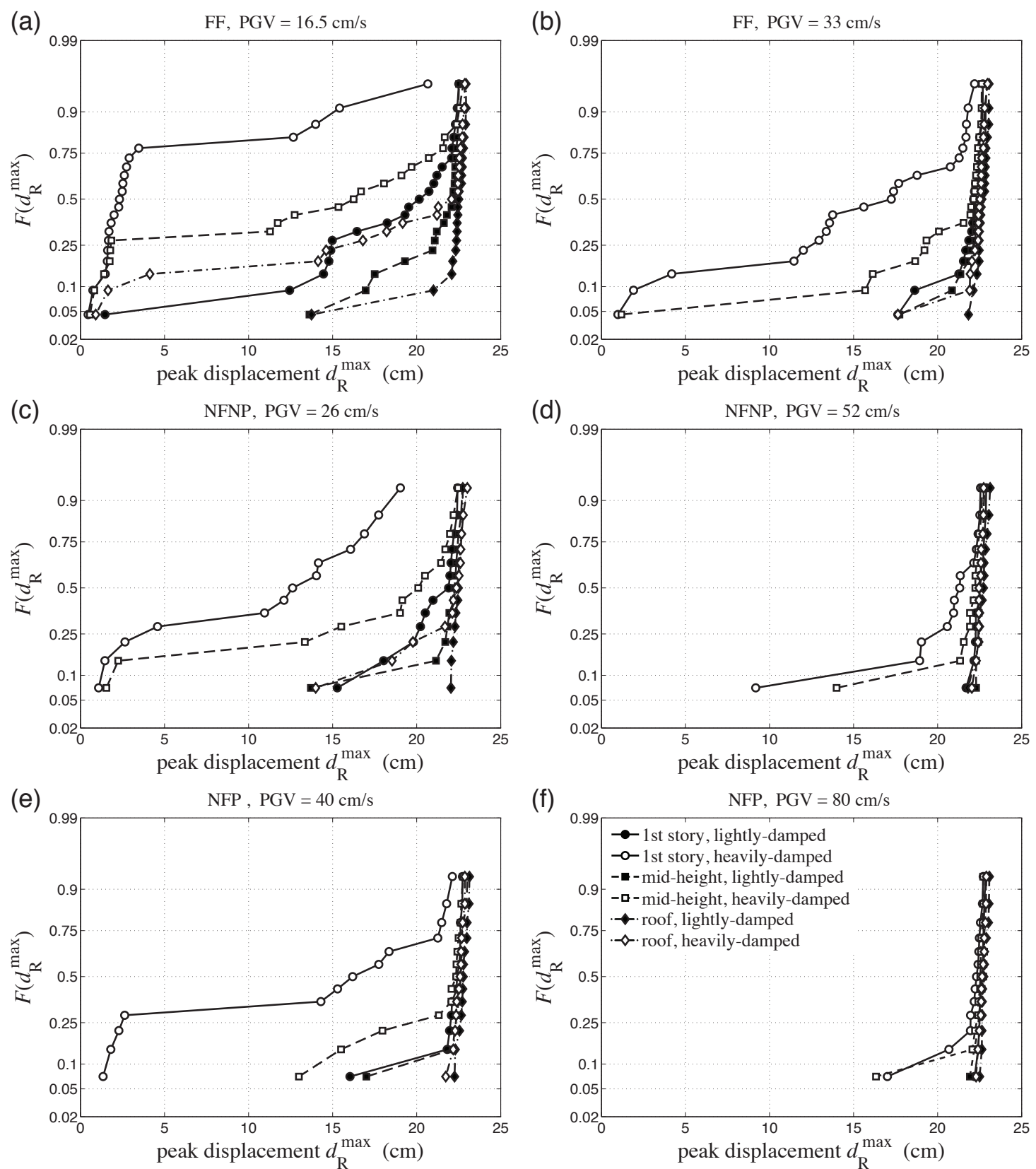

Figure 8: Peak displacement $\left(d_{\mathrm{R}}^{\max }\right)$ empirical CDFs for 4-story, flexible structure: (a) FF, PGV = $16.5 \mathrm{~cm} / \mathrm{s}$; (b) FF, PGV = $33 \mathrm{~cm} / \mathrm{s}$; (c) NFNP, $\mathrm{PGV}=26 \mathrm{~cm} / \mathrm{s} ;$ (d) NFNP, PGV = $52 \mathrm{~cm} / \mathrm{s}$; (e) NFP, PGV = $40 \mathrm{~cm} / \mathrm{s}$; (f) NFP, PGV = $80 \mathrm{~cm} / \mathrm{s}$. 
(a)

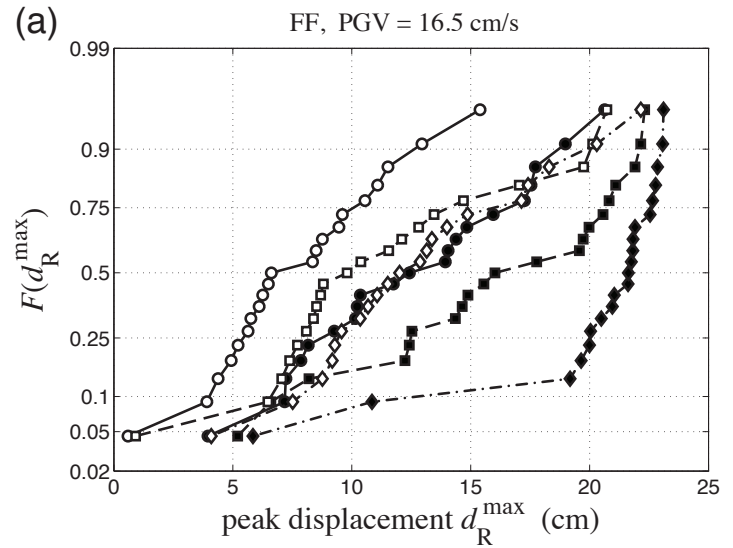

(c)

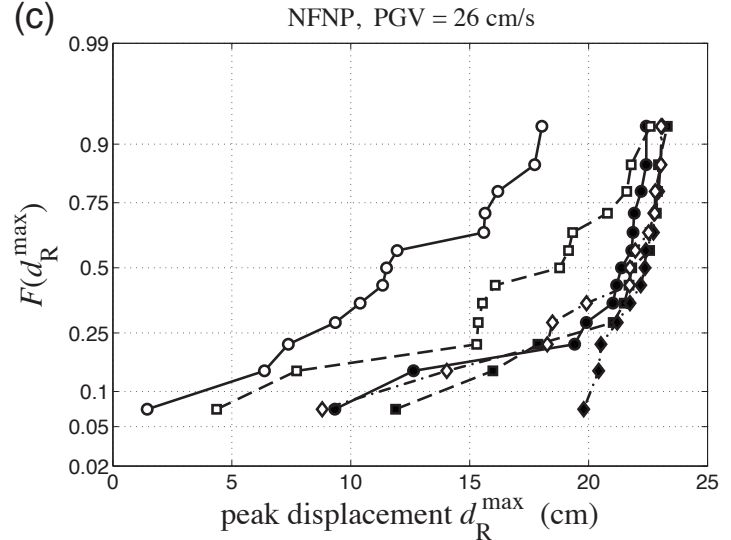

(e)

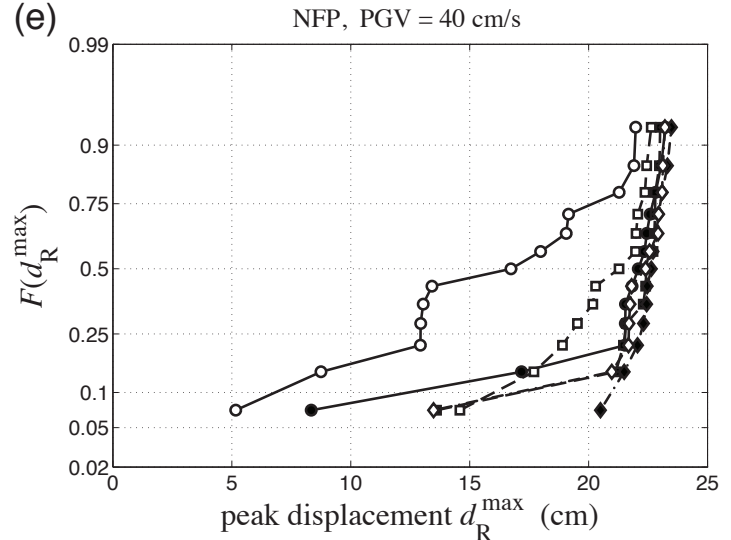

(b)

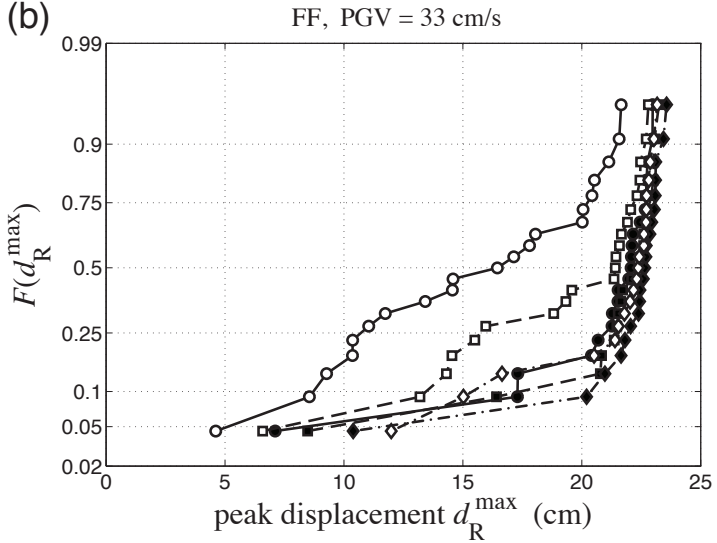

(d)

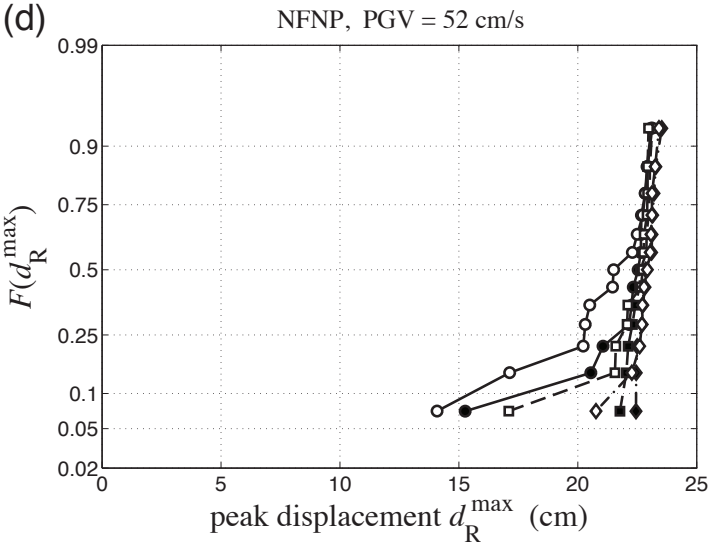

(f)

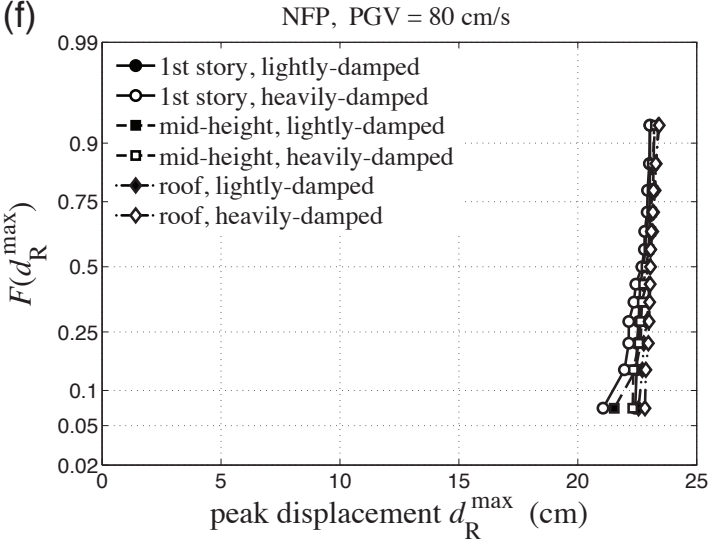

Figure 9: Peak displacement $\left(d_{\mathrm{R}}^{\max }\right)$ empirical CDFs for 4-story, rigid structure: (a) FF, PGV = $16.5 \mathrm{~cm} / \mathrm{s}$; (b) FF, PGV = $33 \mathrm{~cm} / \mathrm{s}$; $(\mathrm{c}) \mathrm{NFNP}$, $\mathrm{PGV}=26 \mathrm{~cm} / \mathrm{s} ;$ (d) NFNP, PGV = $52 \mathrm{~cm} / \mathrm{s}$; (e) NFP, PGV = $40 \mathrm{~cm} / \mathrm{s}$; (f) NFP, PGV = $80 \mathrm{~cm} / \mathrm{s}$. 
(a)

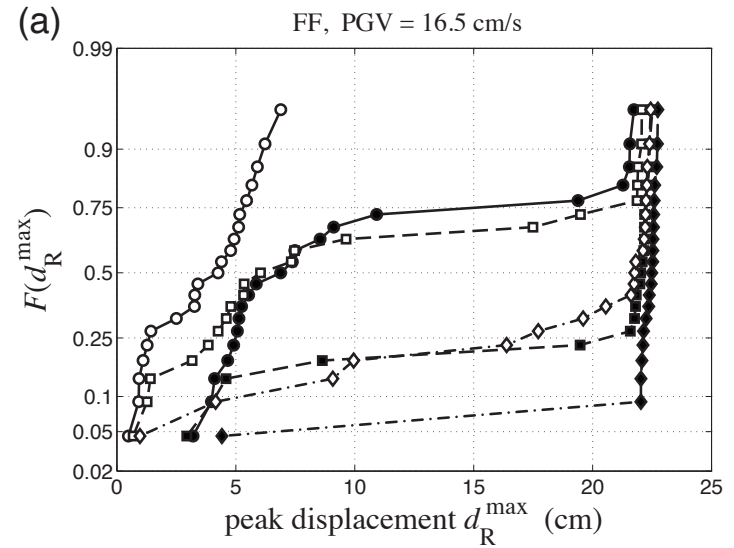

(c)

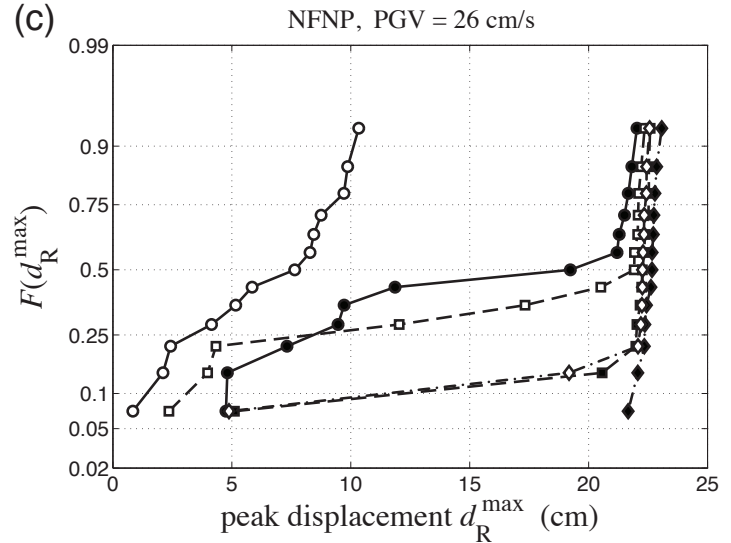

(e)

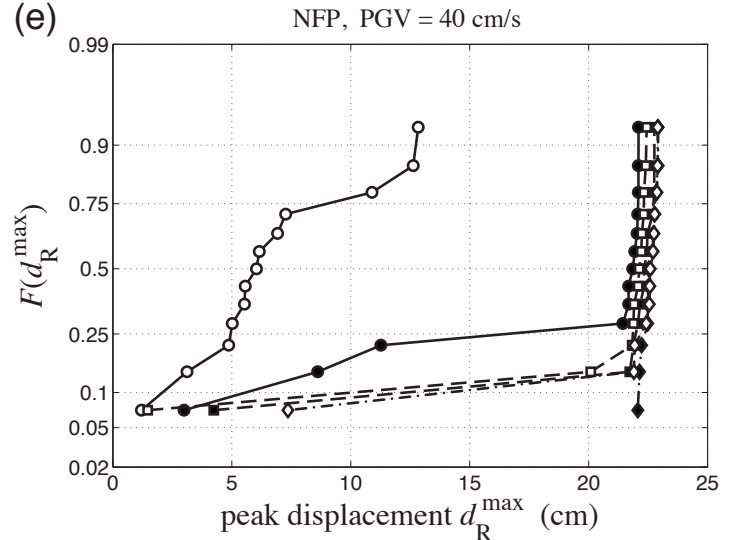

(b)

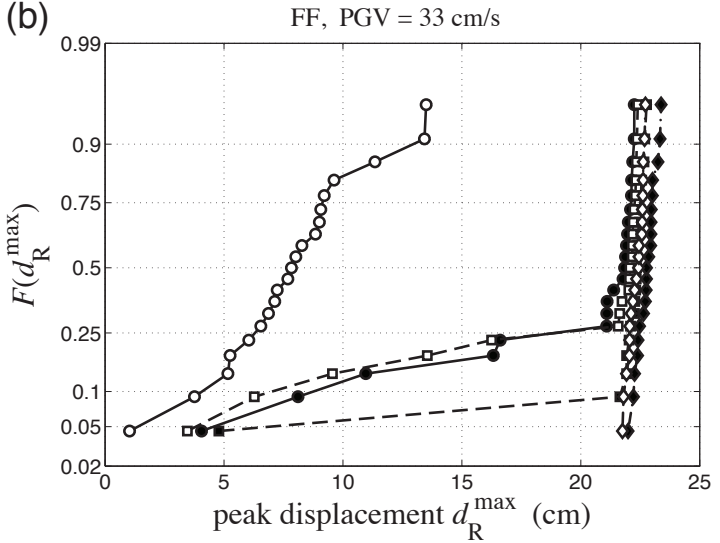

(d)

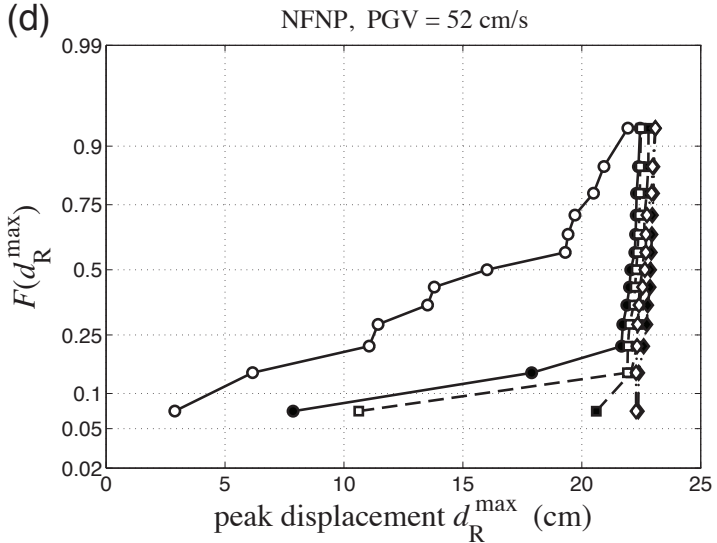

(f)

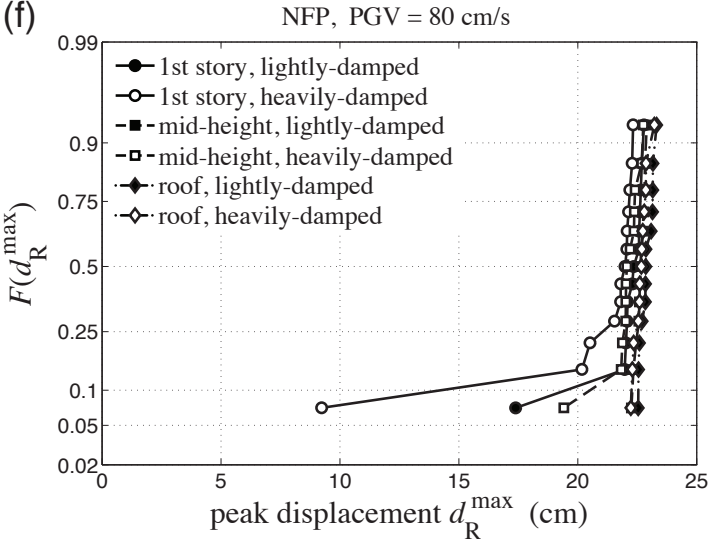

Figure 10: Peak displacement $\left(d_{\mathrm{R}}^{\max }\right)$ empirical CDFs for 8-story, flexible structure: (a) FF, PGV = $16.5 \mathrm{~cm} / \mathrm{s}$; (b) FF, PGV = $33 \mathrm{~cm} / \mathrm{s}$; (c) NFNP, $\mathrm{PGV}=26 \mathrm{~cm} / \mathrm{s} ;$ (d) NFNP, PGV = $52 \mathrm{~cm} / \mathrm{s}$; (e) NFP, PGV = $40 \mathrm{~cm} / \mathrm{s}$; (f) NFP, PGV = $80 \mathrm{~cm} / \mathrm{s}$. 
(a)

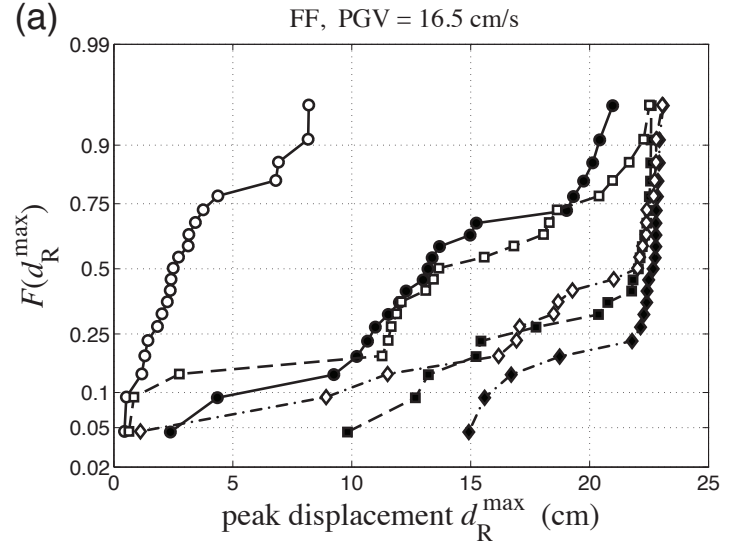

(c)

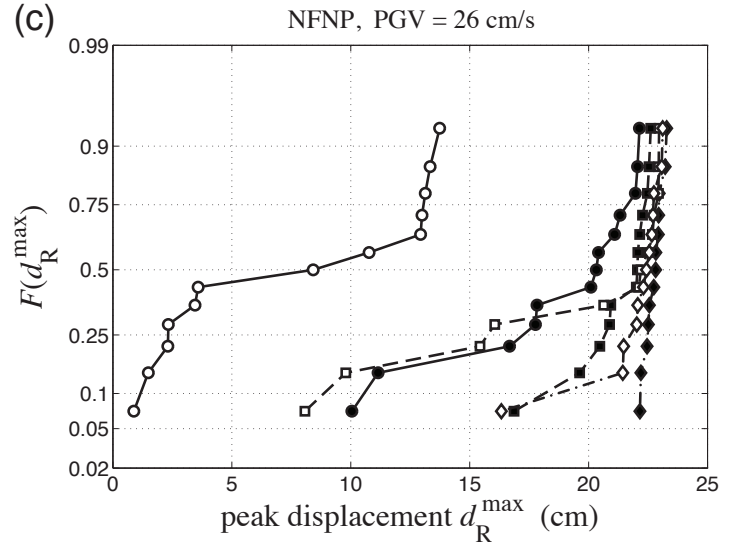

(e)

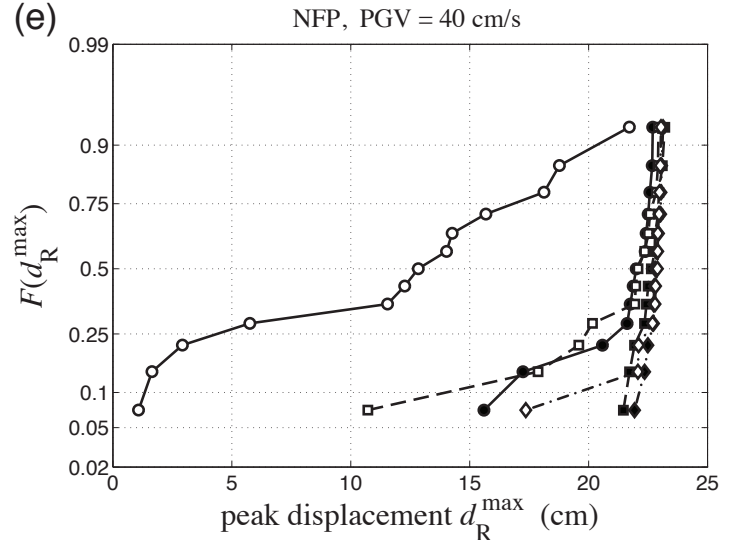

(b)

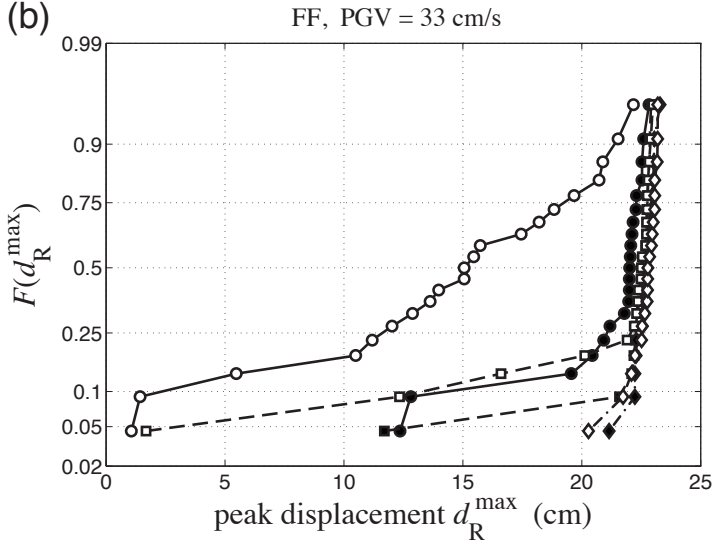

(d)

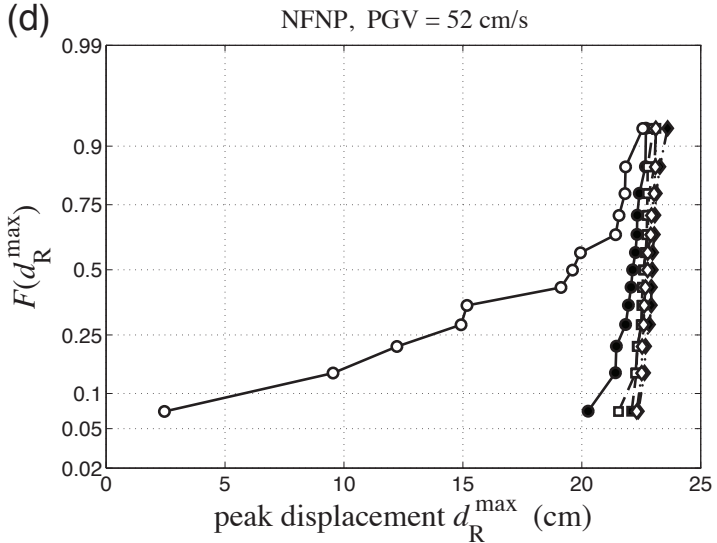

(f)

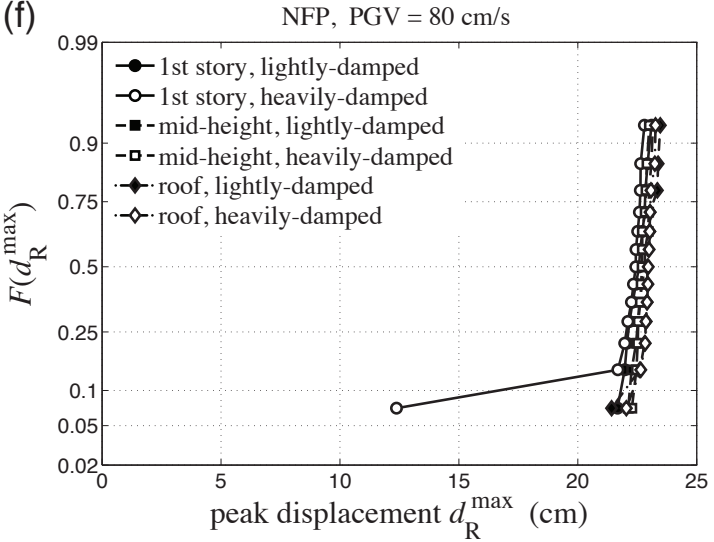

Figure 11: Peak displacement $\left(d_{\mathrm{R}}^{\max }\right)$ empirical CDFs for 8-story, rigid structure: (a) FF, PGV = $16.5 \mathrm{~cm} / \mathrm{s}$; (b) FF, PGV = $33 \mathrm{~cm} / \mathrm{s}$; (c) NFNP, $\mathrm{PGV}=26 \mathrm{~cm} / \mathrm{s} ;$ (d) NFNP, PGV = $52 \mathrm{~cm} / \mathrm{s}$; (e) NFP, PGV = $40 \mathrm{~cm} / \mathrm{s}$; (f) NFP, PGV = $80 \mathrm{~cm} / \mathrm{s}$. 
(a)

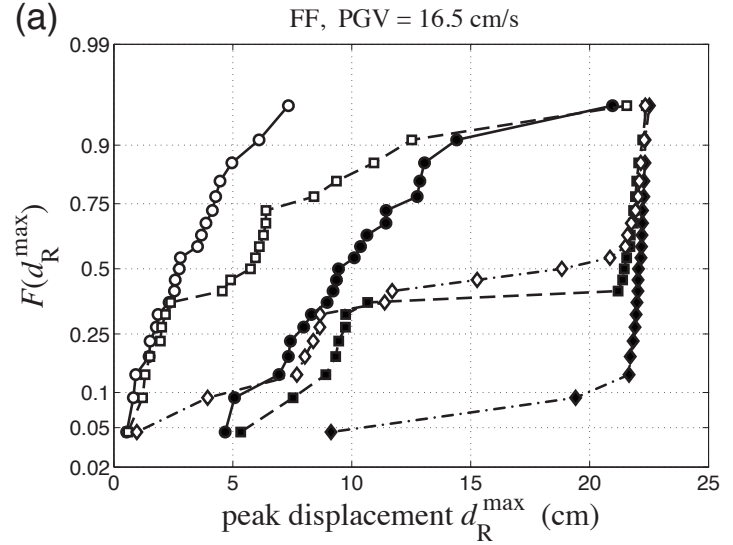

(c)

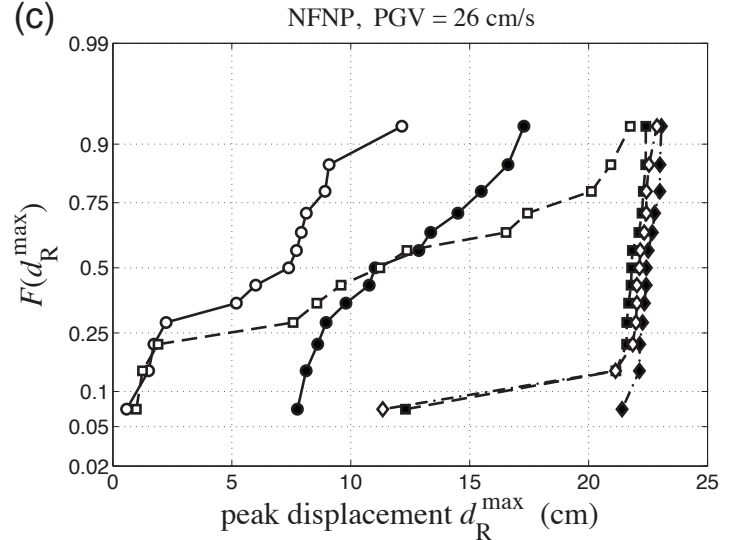

(e)

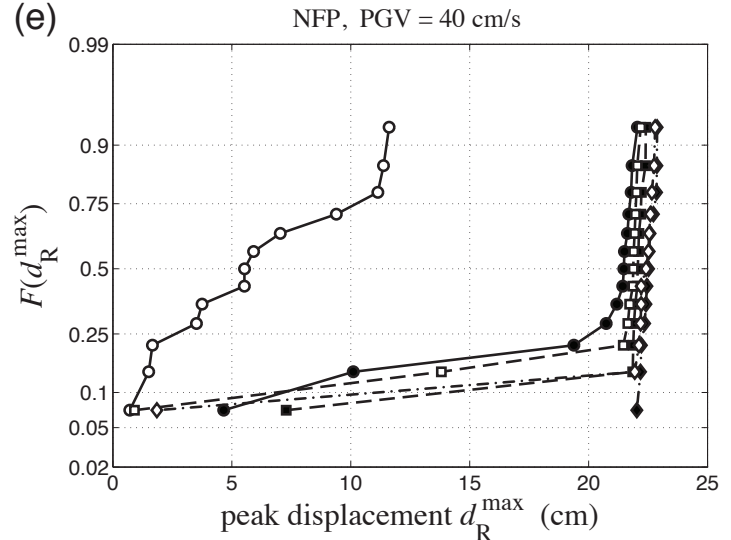

(b)

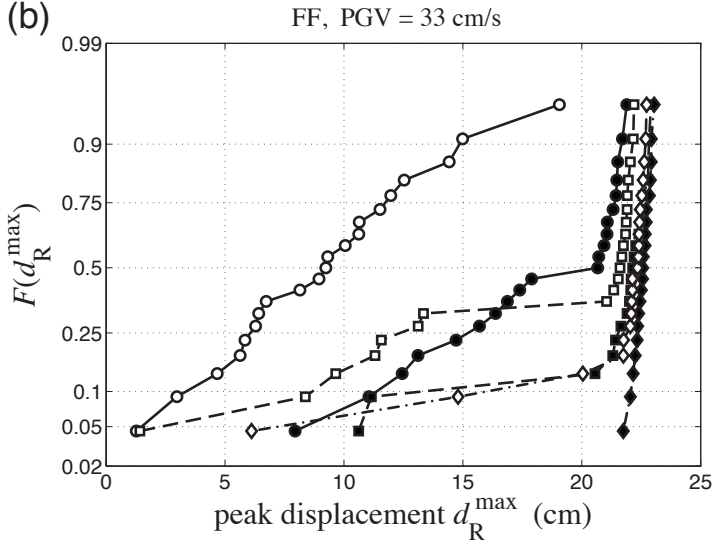

(d)

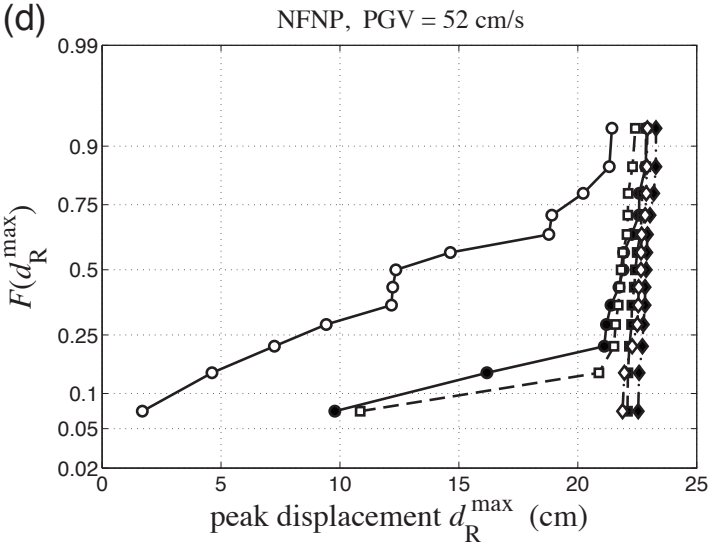

(f)

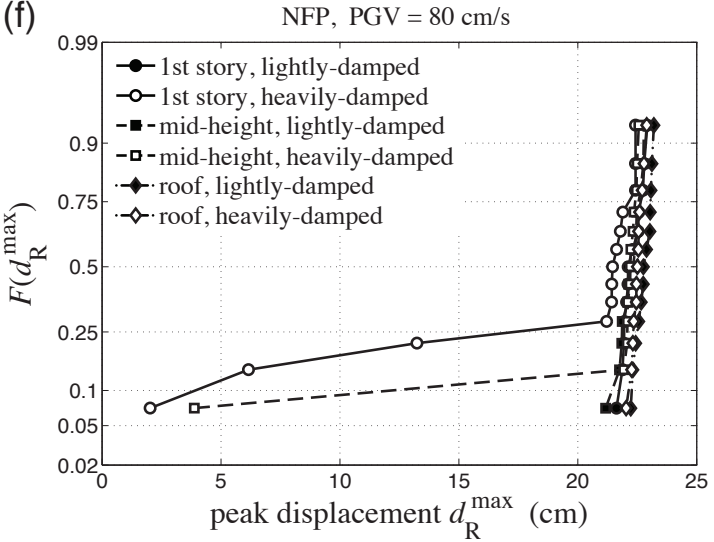

Figure 12: Peak displacement $\left(d_{\mathrm{R}}^{\max }\right)$ empirical CDFs for 12-story, flexible structure: (a) FF, PGV = $16.5 \mathrm{~cm} / \mathrm{s} ;(\mathrm{b}) \mathrm{FF}, \mathrm{PGV}=33 \mathrm{~cm} / \mathrm{s}$; (c) NFNP, $P G V=26 \mathrm{~cm} / \mathrm{s}$; (d) NFNP, PGV = $52 \mathrm{~cm} / \mathrm{s}$; (e) NFP, PGV $=40 \mathrm{~cm} / \mathrm{s}$; (f) NFP, PGV = $80 \mathrm{~cm} / \mathrm{s}$. 
(a)

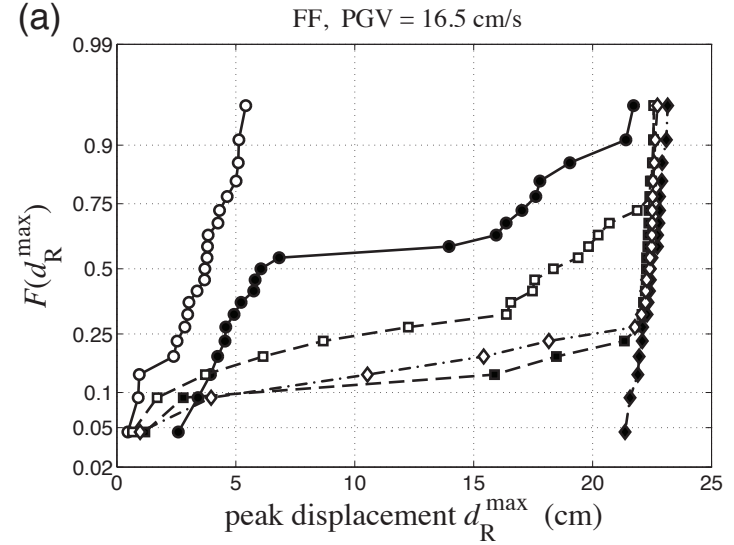

(c)

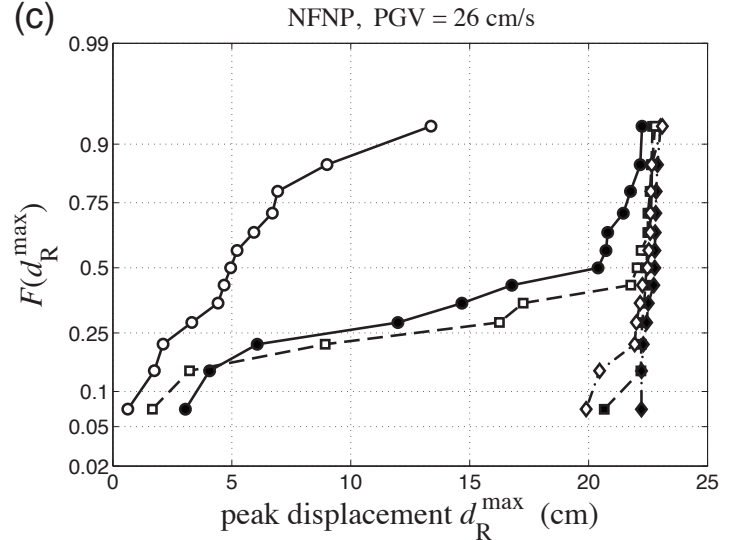

(e)

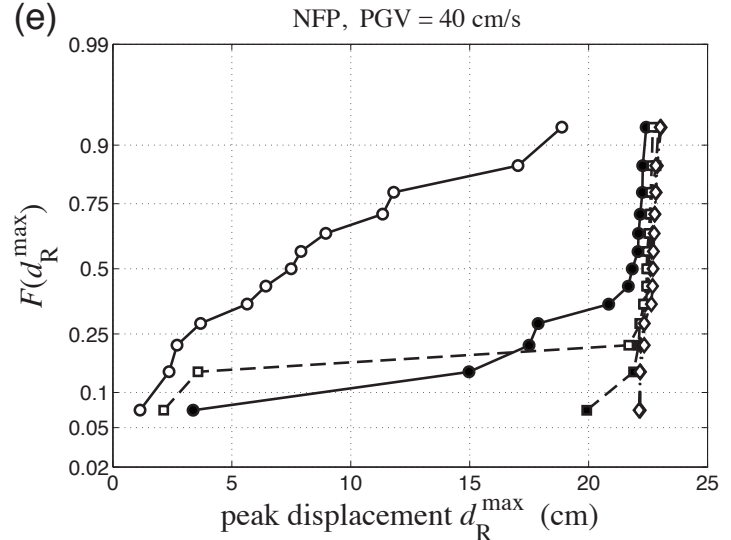

(b)

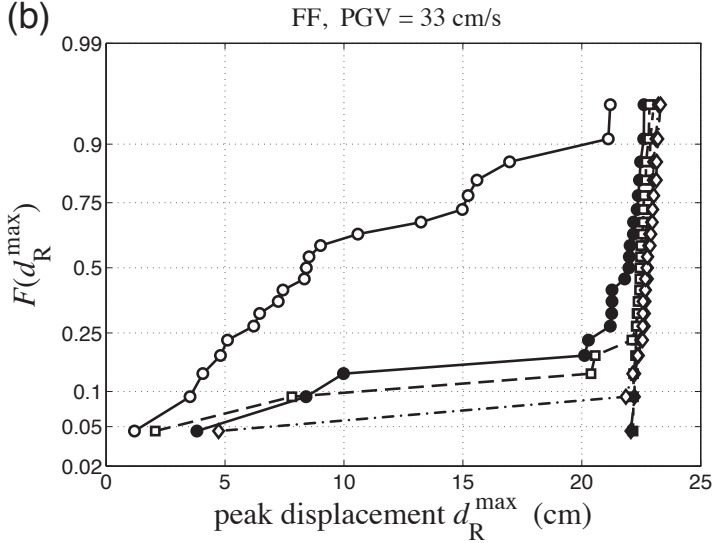

(d)

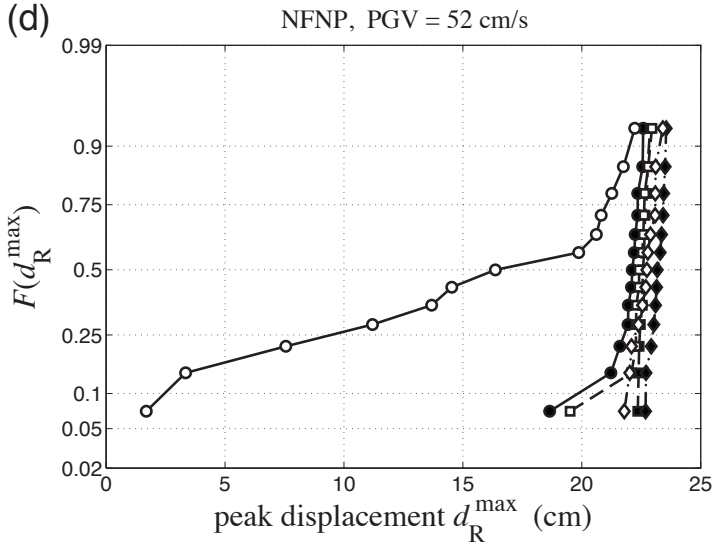

(f)

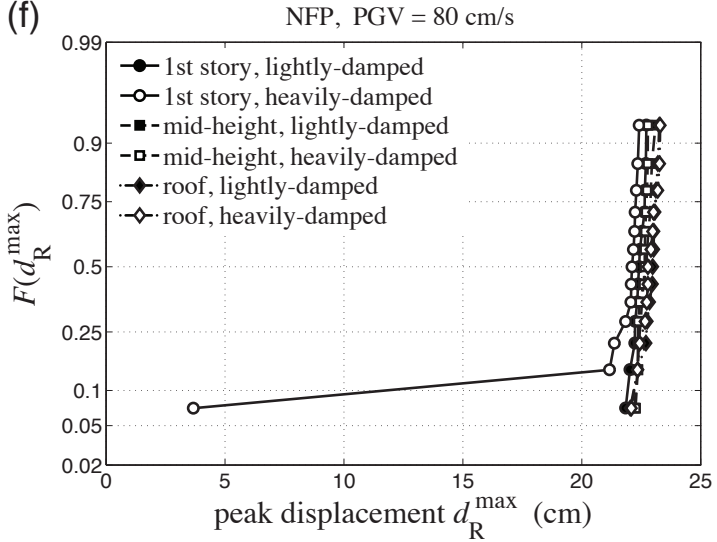

Figure 13: Peak displacement $\left(d_{\mathrm{R}}^{\max }\right)$ empirical CDFs for 12-story, rigid structure: (a) FF, PGV = $16.5 \mathrm{~cm} / \mathrm{s}$; (b) FF, PGV = $33 \mathrm{~cm} / \mathrm{s}$; (c) NFNP, $\mathrm{PGV}=26 \mathrm{~cm} / \mathrm{s} ;$ (d) NFNP, PGV = $52 \mathrm{~cm} / \mathrm{s}$; (e) NFP, PGV = $40 \mathrm{~cm} / \mathrm{s}$; (f) NFP, PGV = $80 \mathrm{~cm} / \mathrm{s}$. 
(a) 4-story, flexible structure; FF, PGV $=16.5 \mathrm{~cm} / \mathrm{s}$

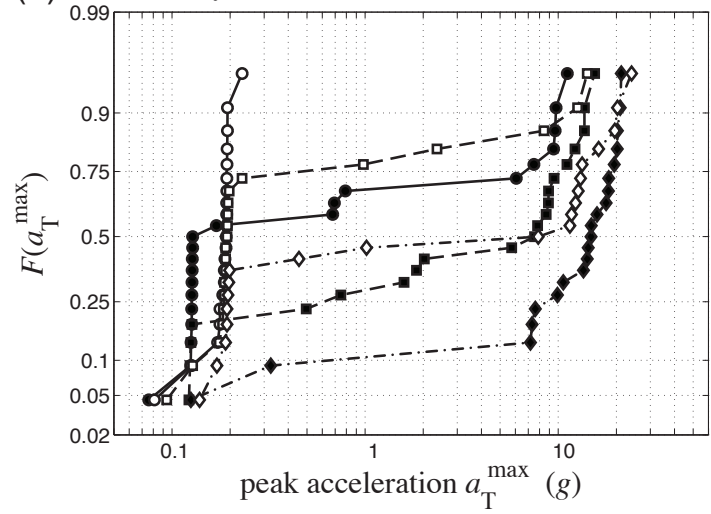

(C) 8-story, flexible structure; FF, PGV $=16.5 \mathrm{~cm} / \mathrm{s}$

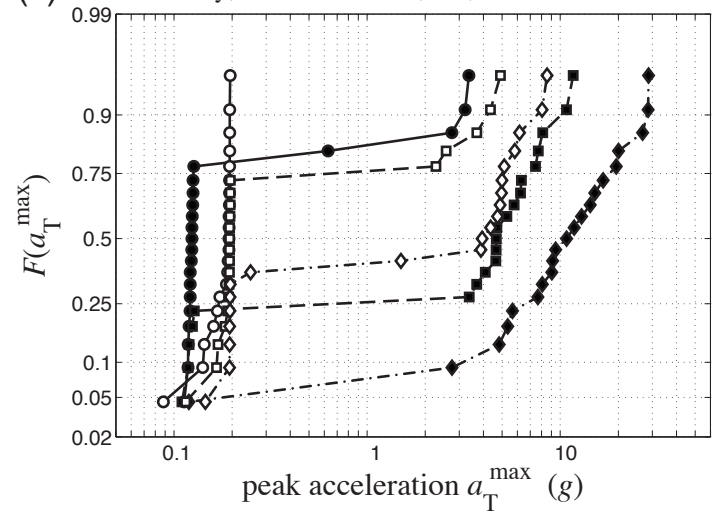

(e) 12-story, flexible structure; FF, PGV $=16.5 \mathrm{~cm} / \mathrm{s}$

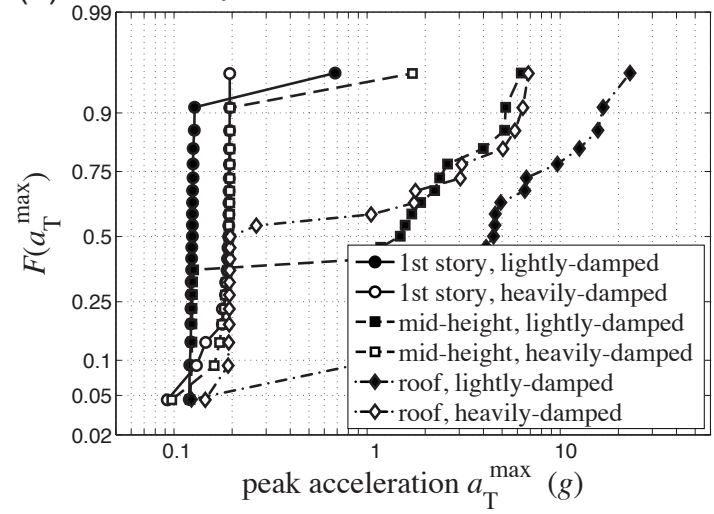

(b) 4-story, flexible structure; FF, PGV = $33 \mathrm{~cm} / \mathrm{s}$

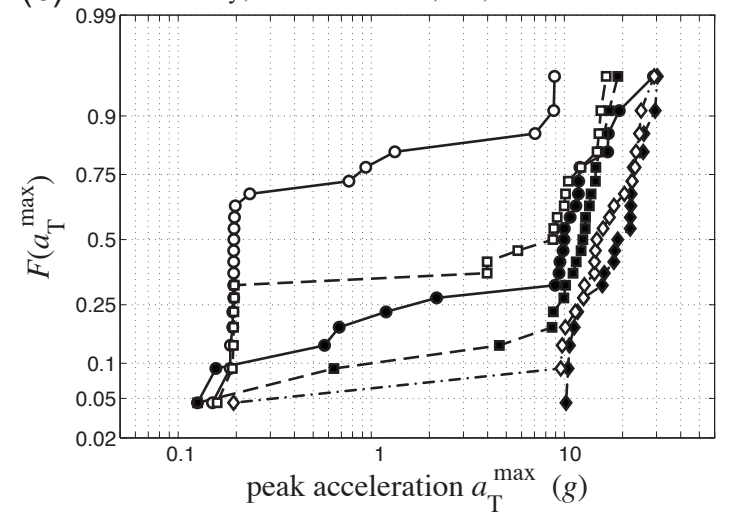

(d) 8-story, flexible structure; FF, $P G V=33 \mathrm{~cm} / \mathrm{s}$

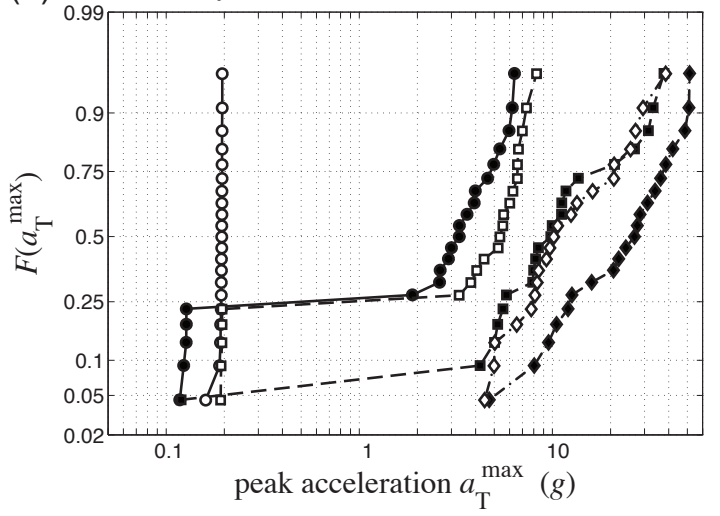

(f) 12-story, flexible structure; FF, $P G V=33 \mathrm{~cm} / \mathrm{s}$

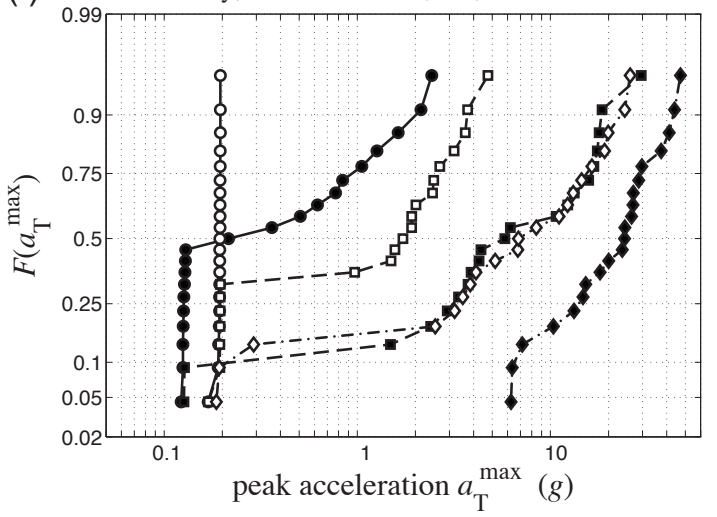

Figure 14: Peak acceleration $\left(a_{\mathrm{T}}^{\max }\right)$ empirical CDFs for flexible structures subject to Far-Field (FF) ground motions: (a) 4-story structure, PGV $=16.5 \mathrm{~cm} / \mathrm{s}$; (b) 4-story structure, PGV = $33 \mathrm{~cm} / \mathrm{s}$; (c) 8-story structure, PGV = $16.5 \mathrm{~cm} / \mathrm{s} ;$ (d) 8 -story structure, PGV = $33 \mathrm{~cm} / \mathrm{s}$; (e) 12 -story structure, $\mathrm{PGV}=16.5 \mathrm{~cm} / \mathrm{s}$; (f) 12 -story structure, $\mathrm{PGV}=33 \mathrm{~cm} / \mathrm{s}$. 
(a) 4-story, rigid structure; FF, PGV = $16.5 \mathrm{~cm} / \mathrm{s}$

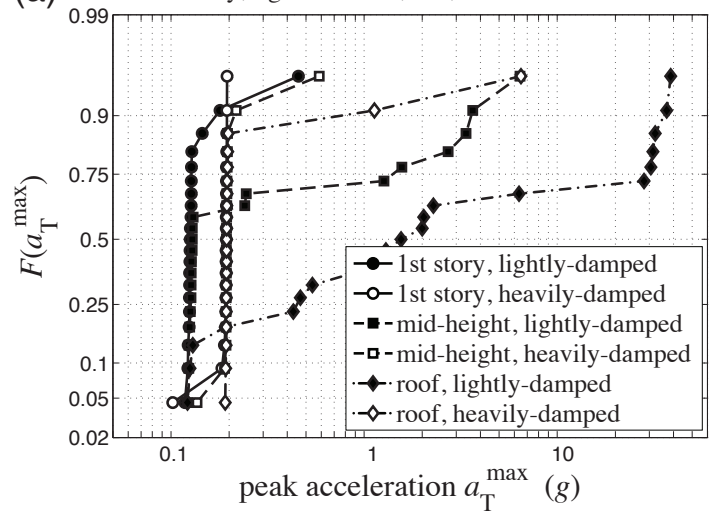

(c) 8-story, rigid structure; FF, PGV $=16.5 \mathrm{~cm} / \mathrm{s}$

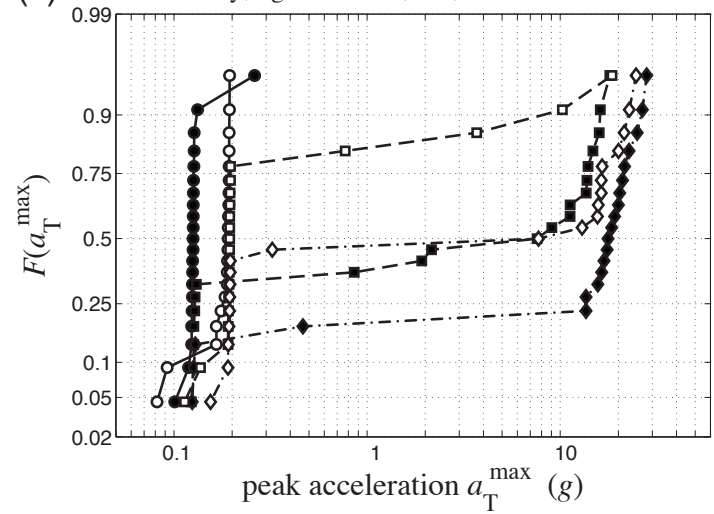

(e) 12-story, rigid structure; FF, $\mathrm{PGV}=16.5 \mathrm{~cm} / \mathrm{s}$

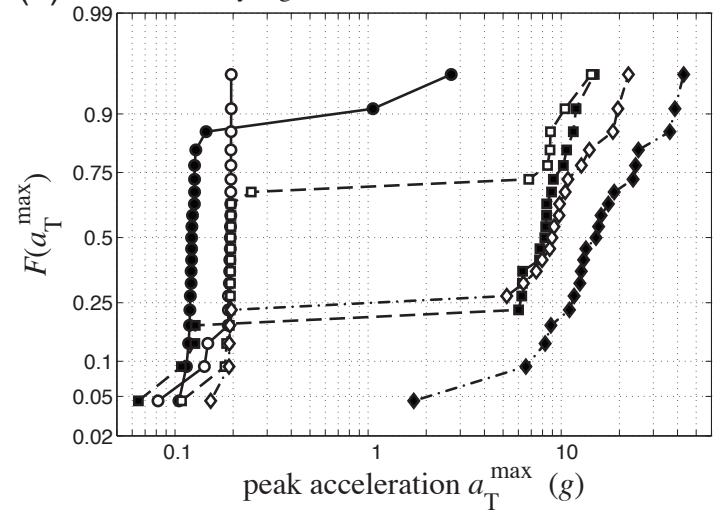

(b) 4-story, rigid structure; FF, PGV $=33 \mathrm{~cm} / \mathrm{s}$

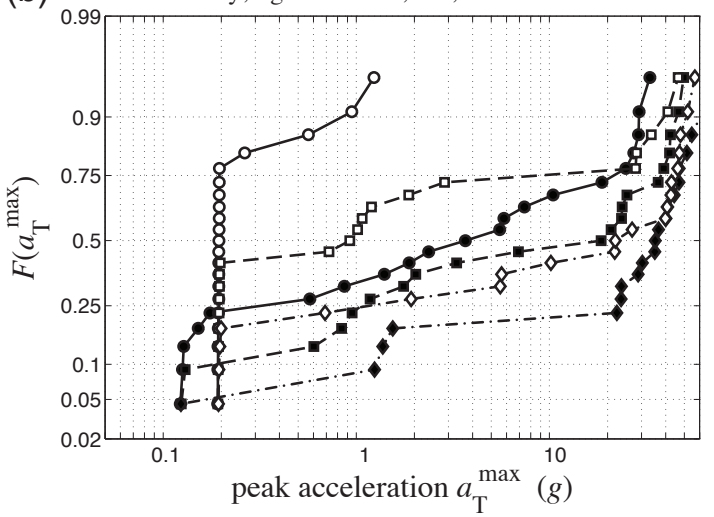

(d) 8-story, rigid structure; $\mathrm{FF}, \mathrm{PGV}=33 \mathrm{~cm} / \mathrm{s}$

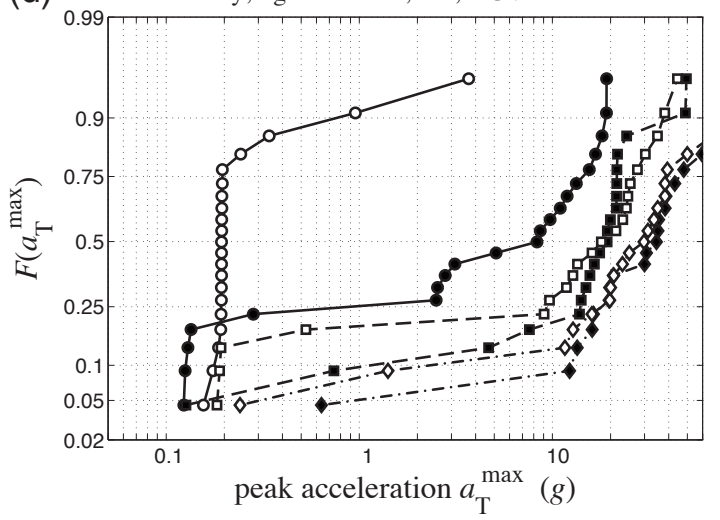

(f) 12-story, rigid structure; FF, $P G V=33 \mathrm{~cm} / \mathrm{s}$

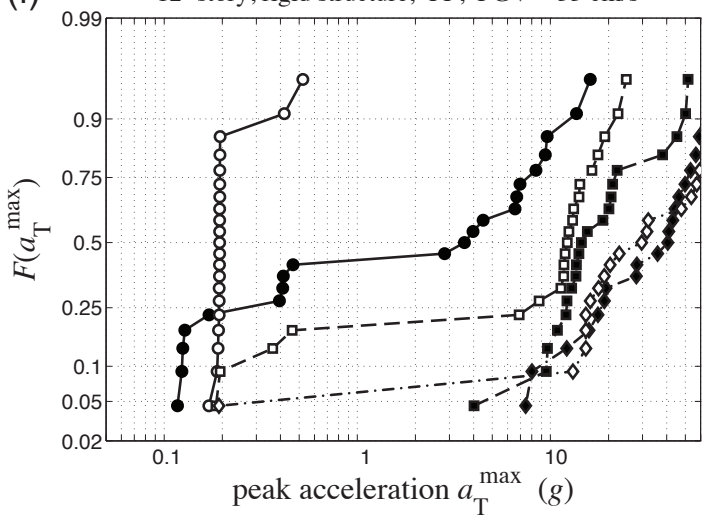

Figure 15: Peak acceleration $\left(a_{\mathrm{T}}^{\max }\right)$ empirical CDFs for rigid structures subject to Far-Field (FF) ground motions: (a) 4-story structure, PGV $=16.5 \mathrm{~cm} / \mathrm{s}$; (b) 4-story structure, PGV = $33 \mathrm{~cm} / \mathrm{s}$; (c) 8-story structure, PGV = $16.5 \mathrm{~cm} / \mathrm{s} ;$ (d) 8 -story structure, PGV = $33 \mathrm{~cm} / \mathrm{s} ;$ (e) 12 -story structure, $\mathrm{PGV}=16.5 \mathrm{~cm} / \mathrm{s}$; (f) 12 -story structure, $\mathrm{PGV}=33 \mathrm{~cm} / \mathrm{s}$. 
Table 4: Far-Field (FF) ground motions selection for present study.

\begin{tabular}{|c|c|c|c|c|c|}
\hline \multirow{2}{*}{$\begin{array}{l}\text { ATC-63 } \\
\text { number }\end{array}$} & \multirow{2}{*}{$\begin{array}{l}\text { PEER } \\
\text { NGA }\end{array}$} & \multicolumn{2}{|c|}{$\operatorname{PSA}(1.0 \mathrm{~s})(g)$} & \multicolumn{2}{|c|}{ PGV (cm/s) } \\
\hline & & comp\#1 & comp\#2 & GM & SRSS \\
\hline 1 & 0953 & 1.02 & 0.94 & 54.2 & 76.5 \\
\hline 2 & 0960 & 0.38 & 0.63 & 43.3 & 56.7 \\
\hline 3 & 1602 & 0.72 & 1.16 & 59.7 & 63.6 \\
\hline 4 & 1787 & 0.35 & 0.37 & 34.2 & 44.1 \\
\hline 5 & 0169 & 0.26 & 0.48 & 29.7 & 33.7 \\
\hline 6 & 0174 & 0.24 & 0.23 & 38.4 & 47.7 \\
\hline 7 & 1111 & 0.31 & 0.29 & 35.7 & 38.5 \\
\hline 8 & 1116 & 0.33 & 0.23 & 32.8 & 44.2 \\
\hline 9 & 1158 & 0.43 & 0.61 & 55.3 & 62.2 \\
\hline 10 & 1148 & 0.11 & 0.11 & 28.5 & 42.7 \\
\hline 11 & 0900 & 0.50 & 0.33 & 36.9 & 56.4 \\
\hline 12 & 0848 & 0.20 & 0.36 & 34.6 & 42.5 \\
\hline 13 & 0752 & 0.46 & 0.28 & 34.5 & 38.3 \\
\hline 14 & 0767 & 0.27 & 0.38 & 43.1 & 49.7 \\
\hline 15 & 1633 & 0.35 & 0.54 & 47.3 & 54.7 \\
\hline 16 & 0721 & 0.31 & 0.25 & 45.2 & 52.4 \\
\hline 17 & 0725 & 0.33 & 0.34 & 30.9 & 35.9 \\
\hline 18 & 0829 & 0.54 & 0.39 & 47.9 & 51.4 \\
\hline 19 & 1244 & 0.49 & 0.95 & 87.5 & 115.0 \\
\hline 20 & 1485 & 0.30 & 0.43 & 38.9 & 46.9 \\
\hline 21 & 0068 & 0.25 & 0.15 & 18.2 & 19.7 \\
\hline 22 & 0125 & 0.25 & 0.30 & 25.1 & 31.0 \\
\hline
\end{tabular}


Table 5: Near-Fault without a pulse (NFNP) ground motions selection for present study.

\begin{tabular}{|c|c|c|c|c|c|}
\hline \multirow{2}{*}{$\begin{array}{l}\text { ATC-63 } \\
\text { number }\end{array}$} & \multirow{2}{*}{$\begin{array}{c}\text { PEER } \\
\text { NGA }\end{array}$} & \multicolumn{2}{|c|}{$\operatorname{PSA}(1.0 \mathrm{~s})(g)$} & \multicolumn{2}{|c|}{ PGV (cm/s) } \\
\hline & & comp\#1 & comp\#2 & GM & SRSS \\
\hline 15 & 0126 & 0.81 & 0.42 & 61.5 & 72.0 \\
\hline 16 & 0160 & 0.44 & 0.44 & 53.9 & 55.4 \\
\hline 17 & 0165 & 0.41 & 0.37 & 29.3 & 32.0 \\
\hline 18 & 0495 & 0.53 & 0.29 & 43.2 & 48.1 \\
\hline 19 & 0496 & 0.16 & 0.29 & 30.7 & 35.4 \\
\hline 20 & 0741 & 0.55 & 0.45 & 49.0 & 56.4 \\
\hline 21 & 0753 & 0.53 & 0.50 & 49.7 & 56.0 \\
\hline 22 & 0825 & 0.42 & 0.73 & 90.4 & 128.3 \\
\hline 23 & 1004 & 0.62 & 1.00 & 74.2 & 78.4 \\
\hline 24 & 1048 & 0.81 & 0.40 & 48.0 & 63.4 \\
\hline 25 & 1176 & 0.38 & 0.35 & 60.5 & 72.9 \\
\hline 26 & 1504 & 0.75 & 0.75 & 72.4 & 99.4 \\
\hline 27 & 1517 & 2.54 & 0.86 & 92.6 & 119.5 \\
\hline 28 & 2114 & 0.69 & 0.82 & 96.1 & 146.5 \\
\hline
\end{tabular}

Table 6: Near-Fault with a pulse (NFP) ground motions selection for present study.

\begin{tabular}{|c|c|c|c|c|c|}
\hline \multirow{2}{*}{$\begin{array}{l}\text { ATC-63 } \\
\text { number }\end{array}$} & \multirow{2}{*}{$\begin{array}{l}\text { PEER } \\
\text { NGA }\end{array}$} & \multicolumn{2}{|c|}{$\operatorname{PSA}(1.0 \mathrm{~s})(g)$} & \multicolumn{2}{|c|}{ PGV $(\mathrm{cm} / \mathrm{s})$} \\
\hline & & comp\#1 & comp\#2 & GM & SRSS \\
\hline 1 & 0181 & 0.43 & 0.60 & 83.5 & 117.4 \\
\hline 2 & 0182 & 0.66 & 0.64 & 79.2 & 109.4 \\
\hline 3 & 0292 & 0.25 & 0.41 & 46.9 & 52.4 \\
\hline 4 & 0723 & 0.97 & 0.51 & 77.2 & 115.9 \\
\hline 5 & 0802 & 0.47 & 0.32 & 48.5 & 55.9 \\
\hline 6 & 0821 & 0.98 & 0.37 & 73.0 & 95.5 \\
\hline 7 & 0828 & 0.92 & 0.70 & 69.2 & 98.0 \\
\hline 8 & 0879 & 0.43 & 0.34 & 111.1 & 147.0 \\
\hline 9 & 1063 & 1.96 & 0.47 & 109.2 & 167.0 \\
\hline 10 & 1086 & 0.89 & 0.65 & 95.4 & 131.6 \\
\hline 11 & 1165 & 0.29 & 0.28 & 27.0 & 30.0 \\
\hline 12 & 1503 & 1.33 & 1.10 & 106.0 & 133.6 \\
\hline 13 & 1529 & 0.60 & 0.58 & 93.8 & 117.6 \\
\hline 14 & 1605 & 0.54 & 0.73 & 70.8 & 87.4 \\
\hline
\end{tabular}

